\title{
I PRIMI MOVIMENTI SOCIALISTI IN EUROPA. CONSOLIDAMENTO ORGANIZZATIVO E MOBILITAZIONE POLITICA
}

\author{
di Stefano Bartolini
}

\section{La prima mobilitazione}

Questo saggio tratta della relazione tra socialismo politicoelettorale e socialismo corporato; cioè fra forme di rappresentanza politica e di rappresentanza degli interessi nei primi movimenti socialisti europei, fra il 1860-1880 e il 1940. Il tema è affrontato sotto la duplice dimensione del consolidamento organizzativo e della mobilitazione degli aderenti. La prima si riferisce al processo di instaurazione e consolidamento di organizzazioni specifiche nel canale corporato-di gruppo e in quello partitico-elettorale, e al legame istituito fra di esse. La seconda alla capacità delle medesime organizzazioni di mobilitare soggetti individuali come membri dei sindacati, iscritti al partito e elettori. Nella prima parte il saggio passa in rassegna e discute il tema della mobilitazione politica; successivamente presenta un quadro concettuale dei legami tra i diversi canali di mobilitazione politica; in terzo luogo analizza brevemente le esperienze nazionali dei movimenti socialisti europei in riferimento a tale schema concettuale; infine prende in esame i livelli di mobilitazione elettorale, partitica e sindacale, ricollegandoli a quelli di consolidamento organizzativo.

«Mobilitazione» è un termine ambiguo. Importato dalla teoria e dall'analisi del totalitarismo e in seguito usato in ogni sorta di contesto, indica ormai il complesso processo di auto-mobilitazione ed etero-mobilitazione, dell'essere mobilitati e del mobilitare ${ }^{1}$. La «prima mobilitazione» è consistita nel processo di coin-

Ringrazio Jelle Visser, Hans Hirter e William K. Roche per il loro aiuto nella raccolta dei dati sugli iscritti ai sindacati.

1 Vedi Neumann $(1956,395-421)$.

RIVISTA ITALIANA DI SCIENZA POLITICA / a. XXIII, n. 2, agosto 1993 
volgimento dei cittadini nella fase (post)nazionale e industriale della modernizzazione. Questi sono stati gradualmente mobilita$\mathrm{t} i$ in varie sfere diverse da quella della politica: dal capitalismo e dall'industrializzazione nella sfera economica, attraverso strumenti come lo scambio e la moneta, l'estensione del mercato, la mobilità geografica e di lavoro, l'imposizione di tariffe, le procedure e le tecniche del capitale e del credito, la disponibilità di beni e servizi; dalla macchina militare e amministrativa dello stato, come soldati, oggetti delle agenzie amministrative, delle restrizioni o liberalizzazioni delle facoltà (spostamento, residenza, ecc.). Infine, essi sono stati mobilitati culturalmente tramite la scrittura ed altri mezzi di comunicazione di massa, da movimenti ideologici, religiosi, etnolinguistici, da agenzie di socializzazione della cultura dominante a livello nazionale ed anche da intellettuali dissidenti, missionari e altre fonti di informazione ${ }^{2}$. Nell'esperienza occidentale degli ultimi due secoli, la mobilitazione ha acquisito aspetti di auto-sostentamento, con effetti di spillover di ciascuna sfera sulle altre. Una volta avviata, essa ha progressivamente assunto i caratteri di un processo di crescita, in cui al cambiamento quantitativo - nuovo reclutamento e avvicendamento generazionale - si è accompagnato quello qualitativo e strutturale delle principali forme e agenzie.

$\grave{E}$ possibile, perciò, distinguere varie fasi o ondate di mobilitazione politica. Tuttavia, la prima ondata è stata di fondamentale importanza, poiché non solo ha aperto le porte a quelle successive, ma ha anche costituito l'originaria struttura delle opportunità all'interno della quale quelle seguenti hanno dovuto collocarsi. La prima mobilitazione politica è sia una parte del processo globale di mobilitazione dei cittadini nella vita nazionale, sia la fase conclusiva di tale processo, che per poter decollare richiede che le altre forme di mobilitazione abbiano raggiunto un certo livello. Da questo punto di vista, due problemi caratterizzano lo studio della mobilitazione politica:

1) che grado di mobilitazione non-politica (economica/culturale/amministrativa) è necessario affinché la mobilitazione politica possa decollare; che relazione esiste fra livelli e forme di mobilitazione non-politica e livelli e forme di mobilitazione politica. In breve, le precondizioni di «mobilitazione sociale» ${ }^{3}$ del-

2 Sul rapporto fra mobilitazione politica ed altri tipi di mobilitazione, si veda Nettl (1967, 115-122).

${ }^{3} \mathrm{Nel}$ senso inteso da Deutsch (1961). 
la mobilitazione politica. In questo ambito, una fertile tradizione di ricerca ha correlato i processi di prima mobilitazione politica - nella maggior parte dei casi intesi nel senso ristretto di estensione del diritto di voto - ai processi di urbanizzazione, industrializzazione, alfabetizzazione; trasformazione della struttura occupazionale e della comunicazione di massa4;

2) qual è il rapporto tra forme diverse di mobilitazione politica; in particolare quelle che hanno luogo nel canale partiticoelettorale rispetto a quelle nel canale corporato degli interessi. Su questo secondo tema la ricerca comparata è meno abbondantes.

Quest'ultimo tema è oggetto del presente saggio. $\mathrm{Ci}$ occuperemo esclusivamente della «prima» mobilitazione politica, ovvero del processo attraverso il quale ex-sudditi sono stati per la prima volta reclutati in qualità di partecipanti attivi ad iniziative organizzative ed elettorali su scala nazionale volte ad influenzare decisioni politiche $e^{6}$. All'interno di questo processo concentreremo l'attenzione sulle specifiche relazioni fra le diverse forme di mobilitazione sindacale, partitica ed elettorale.

\section{Partiti e gruppi nella prima mobilitazione}

La prima mobilitazione politica verticale e discendente non è stata necessariamente monopolizzata dai partiti politici e dalle organizzazioni d'interesse. Anche i governi, la burocrazia statale, la leadership carismatica ed altri attori si sono dimostrati capaci di promuovere la mobilitazione politica, e persino quella strettamente elettorale. In questo caso, partiti e organizzazioni

${ }^{4}$ Si vedano ad esempio Pride (1970), Flora (1973), Kuhnle (1975), Coulter (1975).

5 Mi viene in mente un solo titolo: Rokkan (1962).

6 Una discussione analitica del concetto di mobilitazione politica è in Nedelmann (1987); in particolare nella prima parte (181-191), in cui viene sviluppata la distinzione fra le tre dimensioni della mobilitazione come «formazione di interessi», «controllo di emozioni» e «sviluppo di capacità strumentali». La definizione generale della Nedelmann della mobilitazione politica come «i tentativi degli attori di influenzare la distribuzione esistente del potere» (199) è troppo ampia per i nostri scopi. Tale definizione nasce dall'insoddisfazione verso altre, che circoscrivono la mobilitazione politica ai processi di legittimazione dell'autorità (Nettl 1967) o attribuiscono un'eccessiva enfasi alla dimensione della strumentalità, nel senso di mobilitazione del controllo delle risorse (così come la intende Tilly 1978). La sottolineatura del «reclutamento dei cittadini nella partecipazione politica attiva» implica un riferimento alle tre dimensioni elencate da Nedelmann. Tuttavia, l'interesse fondamentale e i dati si riferiscono in questo caso allo sviluppo delle capacità strumentali. 
d'interesse si sono trovati in competizione con altre agenzie preesistenti ${ }^{7}$, rimanendo comunque i più importanti attori della mobilitazione iniziale. Occorre pertanto rivolgere una particolare attenzione alla specifica interazione fra la formazione di alternative elettorali nell'arena politica e la strutturazione di organizzazioni di massa nel canale dell'organizzazione degli interessi. L'insieme delle organizzazioni elettorali e di interesse e la loro interazione dipesero dalla struttura delle opportunità politiche e dalle scelte strategiche degli attori mobilitanti durante la formazione e la politicizzazione di una determinata linea di frattura. Attingendo al contributo lasciatoci da Rokkan in questo campo $^{8}$, possiamo compendiare tale processo in un insieme di passaggi analitici che indichiamo di seguito. Abbiamo leggermente modificato la terminologia perché riteniamo che il termine cleavage debba essere riservato alla linea di divisione politicizzata e non al conflitto funzionale, culturale o territoriale che l'ha originata':

1) l'iniziale generazione di opposizioni dovute a differenze di interessi e/o di Weltanschauung prodotte dai macroprocessi di modernizzazione: monetarizzazione, urbanizzazione, secolarizzazione, standardizzazione culturale, industrializzazione, controllo amministrativo e centralizzazione;

2) la cristallizzazione delle linee di opposizione in conflitti sulle politiche pubbliche una volta che (e se) si consolida la centralizzazione del processo decisionale politico ${ }^{10}$;

3) l'emergere di alleanze di imprenditori politici impegnati nel mobilitare sostegno a favore di un complesso di politiche e contro altre;

4) la scelta di strategia di mobilitazione compiuta da tali imprenditori:

a) appoggiandosi su e agendo tramite comunità e reti associative precostituite;

b) appoggiandosi su e agendo tramite lo sviluppo di organizzazioni finalizzate al conseguimento di obiettivi specifici;

7 Daalder (1966) affronta direttamente il problema della misura e delle condizioni in cui $i$ partiti hanno monopolizzato tale ruolo con maggiore o minore successo rispetto ad altre agenzie.

${ }^{8}$ Gran parte dell'opera di Rokkan è dedicata al problema della formazione delle linee di frattura. Il riferimento classico è Rokkan (1970).

- Per l'argomentazione che conduce a questa conclusione, si veda Bartolini e Mair $(1990,213-225)$.

${ }^{10}$ In alcuni casi, come in Svizzera e negli Stati Uniti, ciò non è mai accaduto. 
5) la scelta dell'arena per il confronto tra le risorse mobilitate:

a) aggregazione di voti/membri per la competizione politica/elettorale;

b) azione diretta (scioperi, pressione attraverso dimostrazioni pubbliche; rivolta, rivoluzione, ecc.).

Storicamente, alleanze diverse di imprenditori hanno scelto strategie dissimili, sia in termini di scelta organizzativa (punto 4) sia in termini di scelta dell'arena di confronto (punto 5). Alcuni si sono affidati largamente a preesistenti reti di gruppi associativi, occupazionali, culturali, religiosi; altri, invece, si sono vigorosamente impegnati nello sviluppo della loro specifica arma organizzativa, quanto più possibile distinta ed autonoma dalle altre. Alcuni hanno preferito concentrare gli sforzi per soddisfare le domande in strategie prevalentemente politicoelettorali; altri hanno fatto ricorso con frequenza ad azioni rivendicative più dirette nel mercato e nella società. Strategie differenti in contesti differenti hanno fruttato benefici diversi. Per i nuovi partiti e gruppi, questi benefici andavano dal riconoscimento pubblico e dalla legittimazione politica a conquiste sostanziali attraverso legislazioni specifiche, accordi e negoziati con lo stato e/o altre forze politiche. Nell'analisi dei casi storici, i benefici finali sono di grande importanza. La loro valutazione da parte degli attori ha implicato reazioni di feedback; l'insoddisfazione per $i$ risultati ottenuti ha comportato cambiamenti della strategia organizzativa e dell'arena di confronto.

L'aspetto più importante è il legame fra le varie arene e i tipi di base di mobilitazione. Esso varia considerevolmente a seconda del tipo di interessi e/o di identità che vengono mobilitati, e del carattere generale dell'ambiente del sistema politico in cui questi avanzano le rivendicazioni. La tab. 1 sistematizza le possibili forme di questa interconnessione. Lo schema si inspira ad un breve articolo nel quale Rokkan rispose alle critiche che gli erano state rivolte per aver trascurato l'aspetto della mobilitazione degli interessi nella sua analisi della formazione dei sistemi di partito ${ }^{11}$. Lo abbiamo sviluppato e modificato per adeguarlo alla nostra prospettiva. Nella tab. 1, i due canali di mobilitazione, quello elettorale e quello corporato degli interessi,

\footnotetext{
"La critica era stata avanzata da Alford e Friedland (1974). La risposta, nel cui contesto viene formulato lo schema, è in Rokkan (1977).
} 
TAB. 1. Base organizzativa e relazioni tra canali di mobilitazione

\begin{tabular}{ll|ll}
\multicolumn{2}{l}{ Base organizzativa } & \multicolumn{3}{l}{$\begin{array}{l}\text { Tipo di relazione } \\
\text { tra canali }\end{array}$} \\
\hline canale elettorale & canale corporato & legame & $\begin{array}{l}\text { modo } \\
\text { di rappresentanza }\end{array}$ \\
\hline rete diffusa & nessuna & nessuno & \\
organizzazione & $\begin{array}{l}\text { organizzazione } \\
\text { specifica }\end{array}$ & di «gruppo-cliente» & corporato \\
& $\begin{array}{l}\text { contingente } \\
\text { interdipendenza }\end{array}$ & frammentato & $\begin{array}{l}\text { segmentale } \\
\text { ideologico } \\
\text { territoriale }\end{array}$ \\
\hline
\end{tabular}

sono separati. In entrambi possono essere presenti solo reti diffuse: organizzazioni professionali, di mestiere e di altro genere da un lato; organizzazioni basate sui candidati, sul caucus o sul club dall'altro. All'altro estremo troviamo, in ambedue i canali, organizzazioni ad adesione formale. La mobilitazione, sia elettorale che corporata, può ovviamente svolgersi senza necessariamente dipendere da forme centrali di coordinamento. Solo la mobilitazione degli aderenti al partito dipende necessariamente dal consolidamento di un'organizzazione politica centrale. L'esperienza storica dei partiti dell'Europa occidentale evidenzia varie modalità ${ }^{12}$.

La mobilitazione degli elettori può avvenire senza fare riferimento a specifiche organizzazioni ad adesione formale nel canale corporato o in quello elettorale-partitico, ma semplicemente appoggiandosi su una vasta rete di organizzazioni professionali o di altro tipo. È tipicamente il caso di paesi in cui l'allargamento del suffragio è stato precoce, ha avuto luogo prima delle ondate decisive di urbanizzazione e industrializzazione ed ha anticipato anche la rivoluzione organizzativa. La Francia del Secondo Impero e della Terza Repubblica e gli Stati Uniti esemplificano questa situazione. In questo caso le forme di rappresentanza tendono ad assumere natura territoriale, e non è fa-

12 Importanti considerazioni analitiche riguardo al processo di formazione dei partiti si trovano in Nedelmann (1975), Svasand (1978) e Panebianco (1982). 
cile convertirle in una struttura organizzativa nazionale. La formazione di forti e radicate organizzazioni di massa può rivelarsi assai difficile successivamente.

Un secondo modello è la precoce fondazione di organizzazioni specifiche nel canale elettorale non accompagnate e non sostenute da organizzazioni specifiche nel canale corporato degli interessi. Questo modello classico del liberalismo e conservatorismo britannico (e di altri paesi) procede dal caucus elettorale alle sezioni locali; dalle attività di registrazione degli elettori allo sviluppo del reclutamento e dell'organizzazione. Esso tende ad organizzare il sostegno non lungo una singola e ben identificabile linea di frattura, ma attraverso molte, tramite un insieme di alleanze nessuna delle quali assume preminenza nella piattaforma politica e nella vita organizzativa del partito. Questa modalità può essere associata a partiti sviluppatisi in contesti liberalizzati ma non elettoralmente inclusivi.

I partiti «indiretti», nella terminologia introdotta da Duverger $^{13}$, sono il risultato finale di una mobilitazione politica che si afferma originariamente attraverso una diffusa rete elettorale espressione di specifiche organizzazioni di interesse. Lo sviluppo della mobilitazione nel canale corporato precede la formazione dell'organizzazione politica. Il sostegno dell'organizzazione corporata alla rete elettorale di candidati e associazioni politiche è all'inizio contingente, ed in seguito progressivamente interdipendente. È questa l'esperienza della maggior parte dei partiti confessionali e agrari, e di alcuni partiti socialisti. In questo caso la mobilitazione avviene lungo un'unica e ben riconoscibile linea di frattura definita dalle preesistenti organizzazioni di interesse e ne rappresenta l'escrescenza politica.

$\mathrm{Si}$ può infine distinguere il caso di uno sviluppo relativamente parallelo di organizzazioni specifiche in entrambi gli ambiti, elettorale e corporato. La relazione è di reciproco sostegno e rafforzamento; la rappresentanza è più funzionale che territoriale e si colloca lungo ben definite linee di frattura.

La relazione tra le forme di mobilitazione nei due canali è rappresentata nella seconda parte della tab. 1. Il legame fra organizzazioni corporate ed elettorali può essere assente o molto debole. Può assumere le vesti di un gruppo-cliente, quando le organizzazioni in entrambi i canali mantengono una piena liber-

${ }^{13}$ Duverger (1956). 
tà di contrattazione del sostegno. In questo caso esse si rapportano l'una all'altra nei classici termini del modello pluralista di democrazia; ognuna è «cliente» dell'altra nel rispettivo campo di azione, e scambia sostegno elettorale contro sostegno in termini di politiche. Il legame può essere contingente; cioè espresso attraverso alleanze e coalizioni basate sulla prossimità di interessi e similarità di scopi, ma privo di una solida interpenetrazione organizzativa, ideologica e di personale. Benché strettamente alleate, le due organizzazioni conservano identità organizzative distinte e una latitudine di azione indipendente. Il legame può essere interdipendente; cioè caratterizzato da una profonda interpenetrazione fra organizzazione corporata ed elettorale, che si rafforzano vicendevolmente sulla base della sovrapposizione e dell'interscambio di leadership e membership, della coincidenza della base di sostegno, dell'ampio settore di attività collettive comuni. Infine la relazione può essere di $d i$ pendenza, dove una delle due forme di organizzazione centrale tende a dirigere politicamente e organizzativamente la seconda.

Il modo di rappresentanza non dipende dalla base organizzativa o dal tipo di legame, ma dalla presenza o meno di una relazione monopolistica di rappresentanza in entrambi i canali. Il modo frammentato indica una situazione di frammentazione sia corporata che elettorale. In nessuno dei due canali esiste un'organizzazione unica o predominante che possa reclamare il monopolio della rappresentanza degli interessi ai quali fa riferimento. Il legame fra il settore degli interessi e la politica elettorale risulta dall'esistenza di una pluralità di attori che rivendicano un diritto di rappresentanza. Questa divisione di entrambi i canali è spesso la conseguenza di spinte che si rafforzano a vicenda. La frammentazione ${ }^{14}$ può essere di diverso tipo: a) pluralismo segmentato, ovvero l'organizzazione di subculture in competizione, con una stretta interdipendenza di movimenti sociali, gruppi di interesse, agenzie ed attività culturali ed educative $e$ partiti politici lungo identità culturali caratteristiche (linguistiche, religiose o periferico-culturali) ${ }^{15}$; b) frammentazione

14 Nella letteratura il termine «frammentazione» è abitualmente riservato alle divisioni ideologiche, mentre «segmentazione» fa riferimento alle identità (sub)culturali. Qui, il ricorso al termine frammentazione per comprendere divisioni ideologiche, segmentali e territoriali non è inteso a cambiare i termini della discussione concettuale in questo campo. È una soluzione scelta faute de mieux non disponendo di un termine onnicomprensivo migliore che non interferisca con significati largamente accettati.

is Cfr. Val Lorwin (1971). 
ideologica lungo la più classica dimensione competitiva destrasinistra ${ }^{16}$; c) frammentazione territoriale. In questa sede, non ci dilungheremo sulla discussione e sulle implicazioni di queste diverse forme di frammentazione.

Il modo di rappresentanza etichettato come corporato richiede per definizione un legame di interdipendenza fra i due canali. Esso indica una situazione caratterizzata da un monopolio biunivoco della rappresentanza. L'organizzazione degli interessi è l'unica o la predominante rappresentante nel canale corporato di una ben definita fascia di popolazione $e$ l'organizzazione elettorale alla quale è collegata presenta le stesse prerogative in quello elettorale-parlamentare. Il monopolio della rappresentanza esiste pertanto sia nel canale corporato che in quello elettorale.

Le categorie dello schema raffigurato nella tab. 1 sono analitiche. Nei casi storici, raramente un modo di rappresentanza può essere descritto in modo soddisfacente come puramente corporato o frammentato; raramente un legame sarà completamente assente $o$ assolutamente contingente. Inoltre, anche in uno stesso paese, le basi organizzative, i legami e le modalità di rappresentanza cambiano a seconda del settore di interessi e dell'area politica. Una legame di tipo «gruppo-cliente» può collocarsi accanto ad uno di interdipendenza in un altro settore. Ciò che conta è la natura predominante. Non tutte le combinazioni sono d'altronde possibili. I legami di interdipendenza richiedono organizzazioni specifiche in almeno uno dei canali; fra reti diffuse, i legami non possono essere che contingenti. Il modo di rappresentanza frammentato può essere caratterizzato $\mathrm{da}$ connessioni sia contingenti, sia interdipendenti. Infine, lo schema può essere usato diacronicamente, per esaminare lo sviluppo nel tempo del rapporto fra i due canali; oppure sincronicamente, per caratterizzare diversi tipi di rapporto in ogni determinato momento. Per esempio, all'interno dello schema è possibile seguire il percorso della mobilitazione cattolica nell'Europa occidentale: dalle prime reti di organizzazioni culturali e religiose che sostenevano con un collegamento contingente gruppi altrettanto diffusi di candidati nel canale elettorale, sino alla cristallizzazione di specifiche organizzazioni interdipendenti tanto nel canale elettorale quanto in quello corporato. Nel con-

${ }^{16}$ Cfr. Sani e Sartori (1990). 
tempo, si può tipologizzare attraverso lo schema la natura di uno specifico partito o di una famiglia partitica. Ad esempio il gollismo; prototipo di partito elettorale, privo di relazioni speciali con organizzazioni del canale degli interessi e che mantiene con esse rapporti contingenti.

E allettante prolungare questa discussione e porre lo schema in connessione con gli esempi storici che meglio si adattano alle sue categorie; controllare se i casi più difficili possano esservi correttamente inquadrati, e se l'interazione delle sue categorie aiuti a comprendere le implicazioni delle diverse configurazioni ${ }^{17}$. In questo saggio, tuttavia, circoscriveremo l'analisi al caso delle organizzazioni collocate all'interno della frattura di classe: il socialismo sindacale, partitico ed elettorale.

\section{Il primo socialismo sindacale ed elettorale in Europa occidentale}

$\mathrm{Al}$ contrario di altri cleavages, per quello di classe si può attribuire un ruolo secondario alle agenzie culturali e concentrarsi su quelle economiche. In modo simile ai partiti agrari, quelli socialisti sono visti in genere come un'estensione o un'articolazione parallela di organizzazioni già attive nel canale corporato. La tendenza era di partire da una risposta su base economica per andare verso la moltiplicazione delle organizzazioni culturali e politiche costruite attorno ad identità economy-oriented. Il risultato è stato lo sviluppo di organizzazioni specifiche tanto nel canale corporato quanto in quello politico. Questo schema manifesta però significative differenze interne anche alla più rapi$\mathrm{da}$ ricognizione storica. Se si assume come punto di riferimento il momento della formazione di una organizzazione centralizzata a livello nazionale in entrambi $i$ canali - cioè la fondazione di partiti nazionali e di confederazioni sindacali dotate di un centro nazionale - le differenze fra $\mathrm{i}$ contesti nazionali in termini di opportunità, difficoltà e scelte sono ragguardevoli. Quella che segue è una rassegna paese per paese delle origini delle organiz-

17 Si consideri, ad esempio, la possibilità di analizzare le opportunità di accesso e di influenza delle organizzazioni di interesse a seconda del modo di rappresentanza prevalente e del legame che esse hanno con l'organizzazione elettorale: di dipendenza, contingente, di «gruppo-cliente» 0 di interdipendenza. La capacità di contrattazione del sostegno di ciascun gruppo corporato è determinata dalla configurazione delle opportunità offerta da tali combinazioni. 
zazioni socialiste, centrata esclusivamente sulla relazione fra il consolidamento nelle sfere di azione economica e politica nella fase precedente la Prima guerra mondiale.

Austria. L'inizio degli sforzi organizzativi del socialismo austriaco ha assunto la forma delle associazioni culturali. Un importante punto di svolta dello sviluppo nazionale fu la fondazione nel 1867 dell'Erste Allgemeine Wiener Arbeiter-Bildungsverein, concepita per incoraggiare la formazione civica e culturale degli associati, nucleo dei sindacati che si costituiranno in seguito sulla base dello stesso modello. Il movimento venne duramente represso e si divise profondamente al suo interno; tanto per i sindacati quanto per il partito raggiungere una struttura unitaria fu processo lungo e difficile. $\mathrm{Ci}$ vollero quasi tre decenni prima che l'effettiva centralizzazione nazionale del movimento sindacale venisse raggiunta, nel 1893. Le origini del partito vanno fatte risalire al congresso di Neudörfl del 1874 dell' $A r$ beiter-Bildungsverein, che riuscì a trovare un accordo su un certo numero di posizioni comuni sotto forma di un programma riguardante il diritto di voto, la libertà di stampa, di riunione e di associazione, l'alleanza fra i vari sindacati e il lavoro infantile. Il processo venne formalmente concluso sedici anni dopo, nel 1888-89, sotto la guida di Victor Adler, con la formazione della Sozialdemokratische Arbeiterpartei in Oesterreich (SDAPO); 74 delegati, in rappresentanza di 25.000 lavoratori, si incontrarono con l'esplicito scopo di costituire un partito operaio liberato da influenze e contatti con ambienti liberal-democratici. Va sottolineato che dopo il suo esordio nel 1874 il partito era virtualmente scomparso durante gli anni settanta e ottanta.

Il problema principale dell'organizzazione del movimento socialista austriaco era la necessità di rivolgersi a varie nazionalità. Non soltanto nell'Impero, ma anche a Vienna e in tutte le regioni in cui l'etnia tedesca era predominante, larghe fasce della classe operaia erano composte da cechi, polacchi e membri di altri gruppi slavi. Malgrado il fatto che il socialismo austriaco si sia alla fine scisso (tanto in Austria che in Boemia) per effetto della forza disintegratrice del nazionalismo, l'ambiente ostile e irto di problemi, nonché l'estesa e prolungata repressione governativa produssero una relazione partito-sindacato probabilmente più stretta di qualunque altra nell'Europa continentale. Il sindacato offrì sempre un sostegno quasi incondizionato al partito; riconobbe sin dall'inizio l'importanza dell'azione politi- 
ca e il ruolo essenziale del partito in questo campo. Diversamente da quanto accadde nel movimento socialista tedesco, dove $\mathrm{i}$ sindacati alla fine presero il sopravvento nelle questioni tattiche (in particolare nelle decisioni di sciopero), il sindacato austriaco elaborò sempre le sue decisioni tattiche in stretta consultazione con il partito politico ${ }^{18}$. Va sottolineato anche che nella fase formativa il sindacato non subì competizione politica nell'organizzazione dei lavoratori (come ricordato, dovette far fronte a scissioni nazionali); quasi tutti gli operai organizzati appartenevano ai sindacati strettamente legati al partito socialista sino alla fine della Seconda guerra mondiale ${ }^{19}$.

Belgio. Sebbene alcune società operaie ed alcuni giornali socialisti fossero già attivi nella prima metà del secolo (precoce industrializzazione belga), l'inizio della centralizzazione nazionale può essere cronologicamente situato nel 1857-1860, quando a Ghent venne fondata una Lega Operaia, che raggruppava varie organizzazioni di lavoratori ${ }^{20}$. Dal 1880 in poi si vennero formando un gran numero di federazioni nazionali, ma solo nel 1898 fu costituita una Confederazione sindacale nazionale. Gli storici ritengono che lo sviluppo del sindacalismo e le attività sindacali a livello nazionale furono ostacolati da un movimento cooperativo particolarmente esteso ${ }^{21}$. Anche il movimento politico attraversò un lungo e difficile processo di unificazione nazionale. Dal 1864 al 1885 trascorrono 20 anni di fallimenti e solo nel 1885 le federazioni socialiste di Gand, Bruxelles e Anversa riuscirono ad indire un congresso di tutti i gruppi socialisti. Il Partito Operaio Belga venne fondato come una federazione di 59 associazioni: sindacati locali (20), vari tipi di associazioni operaie, cooperative e società di mutuo soccorso.

Il rapporto partito-sindacato in Belgio merita un'analisi più approfondita. Formalmente, la creazione di una confederazione sindacale nazionale (CGTB) fu un evento posteriore, un risultato delle attività del partito. Fu su sollecitazione dei 20 sindacati locali collettivamente affiliati al partito che nel 1898 , al congres196-213).

18 Per la comparazione Germania/Austria su questo punto cfr. Steenson (1991,

19 Le fonti per la storia delle origini del socialismo austriaco sono Steiner (1964), Knopp (1980) e Klenner (1951).

${ }^{20}$ Ghent fu anche il luogo d'origine del primo sindacato cattolico nel 1866.

${ }^{21}$ Spitaels (1974, 9-21). 
so di Vervien, il POB studiò l'opportunità di formare un Comitato Centrale dei Sindacati, embrione della CGTB. La Commission Syndicale, nominata dall'esecutivo del partito, non aveva una linea politica indipendente (anche se il Comitato Centrale era in linea di principio aperto a sindacati di tutte le tendenze politiche). Solamente nel 1907 il Comitato ottenne statuti e congressi propri. Alcuni esperti sostengono che sin ad allora il Partito Operaio Belga tenne il movimento sindacale «sotto il diretto controllo del partito»; affermazione corretta se si guarda alla relazione formale con la Confederazione sindacale nazionale. Tuttavia il partito continuò, ed avrebbe continuato in seguito, a trarre gran parte della propria forza dallo straordinario (e assolutamente eccezionale in termini comparativi europei) sviluppo del movimento cooperativo e mutualistico, le cui espressioni figuravano fra gli elementi costitutivi dello stesso partito. Se il partito favoriva la centralizzazione del sindacato, altre forme di organizzazione corporata in effetti alimentavano il partito. Questa situazione testimonia certamente le difficoltà che il sindacato belga incontrava nell'organizzarsi autonomamente al centro senza un ausilio esterno di coordinamento. Sarebbe tuttavia improprio descrivere tale modello come dominato dal partito $^{22}$.

Danimarca. Nel caso danese, gli sforzi per unificare sul piano nazionale il movimento socialista nel canale corporato e in quello politico-elettorale iniziarono assieme negli anni Settanta del XIX secolo. Nel 1871 alcune federazioni di mestiere dettero vita alla Federazione Danese della Prima Internazionale. Dopo la sua repressione e dissoluzione l'anno seguente, nel 1874 venne fondato il Comitato Centrale dei Sindacati Liberi (FTUCC), un'organizzazione socialdemocratica forte di 6.000 membri, ca-

22 Le difficoltà di coordinamento del movimento politico e sindacale socialista belga, malgrado il precoce sviluppo industriale, vengono attribuite a vari fattori: 1) oltre a caratterizzarsi per uno spirito anticlericale e un ardente razionalismo, l'ideologia socialista si diffuse all'inizio attraverso l'emigrazione politica: Buonarroti, Proudhon, Rochefort, Marx e i rifugiati della Comune di Parigi; il che conferì al socialismo belga una originaria matrice ideologica alquanto differenziata; 2 ) nel periodo di formazione il movimento era schizofrenicamente diviso tra una parte fiamminga, in cui predominavano le associazioni cooperative socialiste (non solo come strutture di consumo, ma anche come punto d'incontro di organizzazioni di classe), ed una parte vallone, dove avevano gran peso tendenze anarchiche che si opponevano all'espansione dell'influenza del partito politico. Ancora nel 1885-1890, iniziative politiche e scioperi in Vallonia non erano controllati dal partito ma da militanti anarchici. Si veda Delsinne (1936). 
ratterizzata dall'abituale formula mista sindacale-politica tipica di questa fase in Europa. Nel 1879 il FTUCC cessò di esistere, e questo arrestò lo sforzo di centralizzazione nel canale corporato. Negli anni successivi il neo-costituito Partito Socialdemocratico assunse le funzioni del FTUCC come struttura di coordinamento dei sindacati.

$\mathrm{Al}$ primo «proto»-congresso di partito, nel 1876, 75 delegati rappresentavano 56 organizzazioni, 41 delle quali erano sindacali e 15 politiche. Anche in questo caso di iniziale sviluppo parallelo, la formazione del partito (1878) precedette di quasi 20 anni quella della Confederazione sindacale nazionale. Quest'ultima venne finalmente costituita soltanto nel 1898 da 38 sindacati nazionali e 25 locali, ancora profondamente divisi al loro interno. L'autorità conferita alla nuova confederazione era giudicata deludentemente bassa dai leaders politici socialisti, ma era una notevole concessione da parte delle ancor forti unioni di mestiere ${ }^{23}$. Da allora il sindacato si trasformò in base di massa del partito. I sindacati furono sempre rappresentati da propri membri nell'esecutivo del partito, e quest'ultimo designava 2 suoi rappresentanti nel Comitato Esecutivo della Confederazione Sindacale. Lo sviluppo iniziale del partito avvenne in forte connessione con la rapida ascesa del movimento sindacale, chiaramente orientato verso forme di centralizzazione a livello nazionale ${ }^{24}$.

Finlandia. Il movimento socialista finlandese fu uno degli ultimi a svilupparsi in Europa e, paradossalmente, il primo ad ottenere sostegno elettorale di massa e responsabilità esecutiva a livello nazionale. Le ordinanze delle gilde e numerosi altri statuti concernenti gruppi socio-economici perdurarono assai più a lungo che nel resto d'Europa, rafforzati dall'eredità del mercantilismo svedese e dal burocratismo russo. Soltanto con i provvedimenti legislativi del 1868 , e soprattutto del 1879 , il sistema delle gilde venne abolito e le relazioni di lavoro furono

${ }^{23}$ L'importanza e la persistenza del sindacalismo di mestiere è un tratto distintivo del movimento operaio danese sottolineato dagli storici. Le prerogative delle Gilde non furono smantellate sino al 1862. La loro forza fu probabilmente dovuta alla lenta industrializzazione del paese. Ciò aiuto le Gilde danesi a trasformarsi lentamente in sindacati. Già dal 1895 tutte le ex-Gilde avevano acquisito la forma organizzativa di sindacato. Cfr. Galenson (1952, 10-32).

${ }^{24}$ Per la Danimarca cfr. Galenson (1952), Foverskov e Johansen (1978). 
organizzate su principi «liberali». Tipico della Finlandia è che la forte resistenza e le restrizioni alla libertà di associazione professionale derivarono più dal timore delle autorità russe di veder crescere tendenze rivoluzionarie che da una legislazione che favoriva deliberatamente gli interessi degli imprenditori, peraltro alquanto deboli. In effetti, le prime unioni sindacali locali furono fondate durante gli anni ottanta e le prime federazioni nazionali negli ultimissimi anni del secolo. Sino ad allora, i numerosi movimenti cooperativi e le prime associazioni operaie non avevano un carattere socialista, ma subivano l'iniziativa e l'influenza della borghesia liberale, attivamente impegnata nella ricerca dell'indipendenza nazionale e della liberazione dalla Russia zarista. La liberalizzazione politica iniziò dopo la sconfitta russa nella guerra col Giappone del 1904-1905 e sfociò nella promulgazione nel 1906 della libertà di associazione e nell'immediata formazione a Tampere (1907) di una Confederazione Sindacale Finlandese (SAJ). Malgrado la protezione costituzionale, i tentativi di limitare la libertà di associazione sindacale continuarono comunque sino a quando l'associazione alla Russia non ebbe termine.

I primi sforzi in vista di una centralizzazione nazionale in entrambi i canali vanno fatti risalire all'industriale filantropo Victor Julius von Wright, che nel 1893 cercò di federare le associazioni operaie attraverso il giornale «ll Lavoratore» e nel 1899 fu uno dei principali fondatori del Partito Operaio Finlandese, il cui programma (di Turku) era largamente ispirato a quelli dei predecessori svedesi e tedeschi. Paradossalmente, le sue posizioni strettamente marxiste si combinavano con una marcata preminenza dell'obiettivo dell'indipendenza nazionale e con altre richieste politiche. La coesistenza di un atteggiamento iniziale fortemente critico verso le istituzioni parlamentari $e$ della preminenza della richiesta di riforme politiche è comprensibile se si considera che la politica di «russificazione» aveva fatto dell'Eduskunta una istituzione di scarso significato e che una parte delle classi dominanti si era schierata con lo $\mathrm{Zar}^{25}$. La forte polarizzazione originaria del movimento socialista ebbe come conseguenza una profonda scissione tra comunisti e socialisti, e tale frattura venne sistematicamente alimentata dalla 
burrascosa storia politica del paese dal 1918 al 1930 e durante il periodo $1940-45$.

Anche in Finlandia, perciò, la centralizzazione sul piano nazionale del sindacato giunse dopo quella del partito. Il ritardo non si manifestò soltanto nella sequenza temporale organizzativa, ma anche nella capacità di mobilitazione. Basta menzionare che ancora nel 1914, mentre il partito godeva di un massiccio sostegno elettorale e rivendicava 70.000 aderenti, il sindacato ne dichiarava all'incirca $30.000^{26}$. Le relazioni tra sindacato e partito erano ideologicamente forti, ma organizzativamente frammentate. Dalla guerra civile del 1918 in poi (e sino al suo scioglimento per attività sovversive ordinato da un tribunale nel 1930) il SAJ fu controllato dai comunisti. L'Organizzazione Centrale dei Sindacati Finlandesi (SAK), rifondata nel 1930, era sotto controllo socialista, ma anche se riuscì a mantenere l'unità organizzativa sino a dopo la Seconda guerra mondiale ${ }^{27}$, la sua conflittualità interna era profonda ed endemica. In conclusione, la rappresentanza politica era frammentata ed altamente polarizzata; il socialismo corporato, benché formalmente unificato sul piano organizzativo, soffriva di un'alta conflittualità ideologica interna.

Francia. Il primo sviluppo organizzativo del socialismo francese si svolge seguendo modalità peculiari. È difficile individuare una data d'inizio dei tentativi di coordinamento nazionale e di unificazione del movimento sindacale. Si è tentati di indicare il 1886 , anno in cui fu fondata la prima federazione di portata nazionale di sindacati di diversi ambiti professionali - la Fédération Nationale des Syndicats et Groupes Corporatifs. Dieci anni dopo, nel 1895, venne costituita la CFT, che nel 1902 si fuse con la struttura territoriale delle Bourses de Travail, dando vita a una duplice struttura articolata in unioni settoriali e dipartimentali. Da allora in poi il processo non venne mai realmente completato. Nel 1914 erano ancora più numerose le federazioni

${ }^{26}$ Sulle origini del movimento sindacale finlandese si veda Suviranta (1987, paragrafo 275).

${ }^{27}$ Sino al 1960, quando - come in Francia e in Italia un po' prima - $i$ socialdemocratici moderati si scissero dal SAK e fondarono una propria confederazione che riassunse il vecchio nome di SAJ. Essi accusavano i membri comunisti e socialisti di sinistra del SAK di usare il movimento sindacale per i loro scopi politici. Soltanto nel 1969 la nuova situazione interna ed internazionale consentì una riunificazione del movimento sindacale. 
al di fuori della CGT che quelle al suo interno. I sindacati francesi rimasero organizzativamente deboli, scarsamente coordinati e, dopo qualche esitazione iniziale, critici del socialismo politico e a volte persino in contrasto diretto con esso.

In parte, ciò era dovuto al fatto che l'organizzazione del socialismo politico, invece di costituire un punto di riferimento era fonte di ulteriore debolezza. Alla SFIO occorse quasi un quarto di secolo per unificarsi, e durante quella fase il forte antagonismo e la competizione fra i vari partiti e le varie organizzazioni politiche che si richiamavano al socialismo furono parzialmente responsabili della mancanza di profonde e durevoli connessioni con i sindacati ${ }^{28}$. La lunga egemonia del sindacalismo rivoluzionario sull'avanguardia operaia fece il resto ${ }^{29}$. La SFIO del 1905 era una concentrazione di almeno 5 formazioni distinte (il Partito Operaio Francese di Jules Guesdes, marxista; i Broussisti, da Paul Brousse, gradualista, riformista, vagamente auto-gestionnaire e aperto alla collaborazione borghese; il Partito Socialista dei Lavoratori di Jean Allemande fondamentalmente «operaista», affezionato allo sciopero generale rivoluzionario e a forme estreme di antimilitarismo e anticlericalismo; il Partito Socialista Rivoluzionario fondato da Louis Blanqui e Edouard Vaillant; i Socialisti Indipendenti di Millerand e Jaurès). In Francia, perciò, la centralizzazione del partito è abbastanza parallela all'istituzione di una Confederazione Nazionale; il partito tuttavia non solo non riuscirà ad avere un rapporto proficuo con quest'ultima, ma rimarrà anche sotto l'egemonia di personalità indipendenti a livello politico ed elettorale sino al periodo fra le due guerre. Quando, negli anni venti, questa si-

28 «Il controllo da parte di un partito socialista sarebbe stato tollerabile. Intollerabile era la competizione tra partiti socialisti rivali per il controllo dei giovani sindacati in lotta. La corrente anti-socialista venne rafforzata dall'ingresso di un considerevole numero di anarchici nei sindacati negli anni successivi al 1890s (Val Lorwin 1954, 20. 21).

${ }^{29}$ Malefakis ha sostenuto che le divisioni interne e il ruolo dell'anarco-sindacalismo francese non dovrebbero essere sopravvalutati. La Francia dovrebbe essere assimilata più all'esperienza continentale che ai casi meridionali di Italia e Spagna (Malefakis 1973). Può essere giusto sottolineare più le differenze che le affinità nel ruolo svolto dall'anarco-sindacalismo in Francia rispetto a Italia e Spagna. Tuttavia, quando la comparazione è fatta tra Francia da una parte e Belgio e Paesi Bassi dall'altra - gli altri due paesi nei quali l'anarco-sindacalismo svolse un ruolo importante nella fase iniziale del movimento operaio - il quadro si rovescia e la Francia è indiscutibilmente più vicina ai casi meridionali che a quelli nord-continentali. La classificazione dei paesi nelle comparazioni per coppie può differire da quella in ambito europeo. 
tuazione verrà superata, sia il movimento politico sia quello sindacale si scinderanno per linee ideologiche.

Germania. La Germania viene abitualmente considerata un chiaro caso di predominio del partito sul movimento sindacale nella fase di formazione. Una specifica organizzazione politica (Sozialdemokratische Arbeiterpartei, SAP) venne costituita assai precocemente nel 1875 come risultato di un processo relativamente breve e facile (in termini comparati) di fusione di organizzazioni preesistenti (in particolare l'Associazione Generale dei Lavoratori Tedeschi di Lassalle, nata nel 1863, e l'Unione delle Società Operaie Tedesche di Babel). Da allora sino alla fase di radicalizzazione che precedette la Prima guerra mondiale, il partito mantenne una solida unità organizzativa, ad onta dell'acceso dibattito dottrinario ed intellettuale interno.

Il movimento sindacale fu inizialmente promosso da agitatori politici socialisti, che videro le unioni «in primo luogo come agenti di reclutamento per il movimento politico» ${ }^{30}$. I lassalliani furono particolarmente attivi in questo campo sin $\mathrm{da}$ quando fondarono il primo sindacato tedesco nel settore della produzione dei sigari (1865). Nel 1868 fu creata un'organizzazione sindacale nazionale, la Federazione Generale Sindacale Tedesca (ADGB). Tale organizzazione sindacale tenne una posizione relativamente dipendente, sotto la guida decisiva delle istanze politiche del socialismo tedesco. Questo anche a causa del Sozialistengesetz di Bismarck, che limitava severamente l'attività delle strutture sindacali e le spingeva a ricercare alleati politici. Tale situazione di dipendenza non durò a lungo. Il ruolo inizialmente silenzioso del sindacato nel dibattito teorico interno al partito fra riformisti e rivoluzionari si trasformò con il tempo in un potere dirimente sempre più decisivo. Fino al 1918 il legame non fu né di subordinazione né di eguaglianza, nel senso classico di una divisione del lavoro e dell'esistenza di sfere indipendenti di competenza. Era una forma di «convergenza» dettata dalla comunanza di scopi e dalle modalità di lotta imposte dal sistema autoritario, oltre che dalla cultura e dall'orientamento ideologico profondamente solidaristici della classe operaia. Tutto spingeva a rendere inseparabili gli scopi, le tattiche e le strategie delle due organizzazioni. In quest'ultima posizione non è

30 Schorske $(1955,9)$. 
comunque difficile riconoscere il risultato del precoce imprint del socialismo politico su quello sindacale.

Irlanda. Contrariamente alla Germania, l'Irlanda è il caso più evidente di organizzazione del canale corporato che precede e domina quella del canale elettorale. Quest'ultima rimase a lungo una rete debolmente coordinata di candidati dei sindacati. La fondazione di un'organizzazione sindacale nazionale fu relativamente precoce e rapida. Già nel 1863 esisteva a Dublino una United Trade Association che nel 1868 aderì alla British Trade Unions Conference. A partire dal 1880 la maggior parte delle città aveva la propria associazione sindacale, che di regola aderiva poi alla TUC britannica. La creazione di un'organizzazione sindacale nazionale irlandese nel 1894 (Irish Trade Union Congress) fu il risultato della decisione di separarsi dal TUC britannico, accusato di non curarsi abbastanza degli specifici problemi irlandesi ${ }^{31}$. Questa precocità non deve nascondere il fatto che l'ITUC non fu mai bene organizzata in un paese di industrializzazione tardiva e nel quale prevalevano piccole aziende di proprietà familiare ${ }^{32}$. A causa della persistente presenza $e$ resistenza dell' associazionismo di mestiere, le unioni non riuscirono a darsi un coordinamento efficiente, e rimasero deboli in termini di numero di aderenti ${ }^{33}$. L'ITUC non aveva molta autorità sulle unioni affiliate (spesso nessuna autorità sino a dopo la Seconda guerra mondiale); non si poteva impegnare in contrattazioni collettive né produrre decisioni vincolanti a livello centrale. Parlare di sindacato «nazionale» è un'esagerazione ${ }^{34}$.

Ancora peggiore era però la situazione della mobilitazione politica della classe operaia. La prima organizzazione politica con un programma socialista fu l'Irish Republican Socialist Party (ISRP), fondato nel 1896 dalla leggendaria figura di James Connolly. Ma il partito non «decollò» e fu danneggiato dall'oscura storia dell'emigrazione del suo leader negli Stati Uniti nel 1903. Non si può rivendicare alcuna continuità organizzativa fra

${ }^{31}$ Su questo problema cfr. Berresford Ellis (1972, 167-183).

32 Ancora negli anni sessanta, più dell' $80 \%$ delle 5.000 aziende manifatturiere, edili e di servizi (trasporti, servizi pubblici, ecc.) impiegava al massimo 20 operai (Harbridge House Europe 1967, 32).

${ }_{33}$ Delle 97 unioni sindacali affiliate all'ITUC a metà degli anni sessanta, 51 avevano meno di 1.000 membri su un'affiliazione complessiva all'ITUC di 364.000 aderenti (Chubb 1974, 109).

${ }^{34}$ Sulle origini del movimento sindacale irlandese cfr. Roche (1990). 
l'ISRP e l'Irish Labour Party (ILP), la cui data di fondazione è materia di dibattito fra gli storici irlandesi. Alcuni indicano la data del 1912 per un'organizzazione politica embrionale. Nel 1914, tuttavia, l'ITUC aggiunse la formula «and Labour Party» al suo nome, indicando quantomeno una situazione di minima differenziazione fra le due strutture. Sul piano formale, il partito ottenne un'esistenza indipendente nel 1922, ma solamente nel 1930 la separazione tra ITUC e ILP fu effettiva ${ }^{35}$. Sin dall'inizio l'adesione fu limitata ai Trade Union Councils affiliati. Tutti i tentativi fatti per allargare il reclutamento furono regolarmente sconfitti negli anni venti. E interessante ricordare che il congresso del 1914 si era preoccupato di «impedire ai politici di infiltrarsi nel nuovo partito ${ }^{36}$ ed aveva sancito che tutti i candidati laburisti a cariche pubbliche dovevano essere membri del sindacato. Almeno sino agli anni trenta, il partito rimase sindacalista nel personale e nella mentalità: un partito di sindacalizzati per $i$ sindacalizzati; dopo il 1930 rimase tale nello spirito ${ }^{37}$. La sua funzione era esplicitamente quella di difendere gli interessi del sindacato nel Dail. A differenza di quanto accadde nelle altre esperienze europee, fu l'ILP a subire i conflitti sindacali e le contese intestine e non il contrario. C'era dunque dipendenza, ma non rappresentanza corporata, in quanto né il sindacato né il partito riuscirono mai a diventare l'unico o almeno il dominante portavoce del mondo del lavoro. Soltanto una minoranza della classe operaia irlandese vide l'ILP come il proprio partito.

Italia. L'esperienza italiana assomiglia per molti versi a quella francese, per il fatto che l'organizzazione politica specifica fondata nel $1892 \mathrm{fu}$ il risultato di un difficile amalgama di diverse tendenze e di esclusione di altre. Benché più rapido che in Francia, il processo non è stato meno frammentato. È difficile identificare con chiarezza l'inizio di una fase di centralizzazione politica nazionale anteriore al 1892-93, sebbene l'esperienza del Partito Italiano dei Lavoratori negli anni ottanta vi si sia avvicinata (il Partito Socialista Rivoluzionario di Andrea Costa era fortemente localizzato in Romagna e, oltre ad essere in origine composto soprattutto da contadini e braccianti agricoli, comprendeva una dominante componente anarchica). Le tendenze anarchiche,

35 Sulla storia iniziale del partito, si veda Mitchell (1974).

${ }^{36}$ Mitchell $(1974,85)$.

37 Cfr. Gallagher $(1982,4)$. 
«operaistiche», radical-repubblicane (nell'Italia centrale) vennero alla fine emarginate, ma non scomparvero. La sensazione della necessità di una specifica organizzazione politica si affermò contro forti resistenze. Il Partito Socialista Italiano dei Lavoratori creato nel 1892 (dal 1895 Partito Socialista Italiano) aveva in origine 4 presidenti, per garantire l'autonomia e la rappresentanza della varie componenti ideologiche. La formale posizione marxista appariva più come una sintesi intellettuale che come un coerente insieme di tratti distintivi politici ed organizzativi (l'elaborazione teorica marxista era dovuta principalmente ad intellettuali esterni al movimento socialista, come Labriola e Mondolfo). Sebbene inizialmente l'affiliazione non fosse individuale ma avvenisse attraverso le società operaie, il partito non godeva di profondi legami organizzativi con l'insieme di organizzazioni ed associazioni operaie e socialiste esistenti. Nel 1895, il passaggio all'adesione individuale fu dettato dalla necessità di evitare il rischio di scioglimento delle leghe e delle società di mutuo soccorso a seguito della repressione politica del periodo crispino. Soltanto il partito venne sciolto per breve tempo.

Negli anni successivi alla fondazione, il socialismo politico svolse una funzione importante nell'incoraggiare l'organizzazione sul piano nazionale dei sindacati, che tuttavia non si concretizzò sino al 1906. Il lasso di 14 anni fra la fondazione del partito e la creazione della Confederazione non indica una relazione di dipendenza. Il partito nazionale fu estremamente debole per tutti gli anni novanta e non poté esercitare un ruolo dominante. La relazione tra le due strutture è più simile a quella di tipo francese che a quella tedesca: stretta ma problematica, e senza un chiaro predominio dell'una sull'altra. La confusione di ruoli fra le due organizzazioni si mantenne a lungo; la divisione del lavoro non impedì alla leadership riformista del sindacato di esercitare una specifica azione politica; alcuni settori del movimento sindacale discussero a lungo sull'opportunità di fondare un'organizzazione politica che fosse diretta espressione del mondo del lavoro organizzato ${ }^{38}$. Come in Francia, la politicizzazione del movimento sindacale fu probabilmente espressione della frammentazione ideologica ed organizzativa interna sia del partito che del sindacato ${ }^{39}$.

38 Il partito laburista sognato da Rigola (Cartiglia 1976).

39 Sul rapporto fra partito e sindacato in Italia si vedano Horowitz (1976) e Pappalardo (1989), che passa in rassegna il dibattito storiografico in argomento. 
Paesi Bassi. Nei Paesi Bassi la prima organizzazione politica di ispirazione socialista fu la Lega Socialdemocratica (SDB), fondata nel 1881. La sua creazione fuse i gruppi socialisti delle quattro maggiori città olandesi sotto la guida di un pastore luterano, Domela Nieuwehuis, che nel 1879 aveva abbandonato la Chiesa per dedicarsi alla propaganda e all'organizzazione socialista. Il socialismo olandese rimase a lungo influenzato dalla sua «predicazione», basata su una forte fede umanitaria ed internazionalista, un'accentuazione dei momenti etici rispetto alle specifiche motivazioni politiche socialiste e forti toni antiparlamentari. Dopo l'arresto subìto nel 1886, Nieuwehuis sviluppò concezioni di auto-emancipazione degli operai molto vicine all'anarco-sindacalismo; la sua influenza diminuì progressivamente all'interno del partito, ma rimase forte nel sindacato, dove non venne sconfessata sino al fallimento del grande sciopero del 1903.

Fra il 1881 e il 1894, il processo che conduce alla formazione del Partito Socialdemocratico Olandese (SDAP) è contrassegnato dal conflitto tra le leghe socialiste. Le leghe che vedevano con favore un'azione politico-parlamentare vennero sconfitte nel congresso del 1893 e dettero vita ad una scissione, fondando il SDAP l'anno seguente. Il socialismo politico olandese nacque dunque da una rottura nel movimento socialista, e il suo predominio all'interno di esso non fu acquisito sino all'inizio del XX secolo, quando altre correnti - in particolare quella sindacalista rivoluzionaria - subirono importanti sconfitte strategiche. Al momento della formazione del partito socialista olandese, $i$ sindacati di ispirazione socialista non erano quindi strettamente legati ad esso, ma continuavano a seguire la guida di Nieuwehuis e degli anarco-sindacalisti. Fu questa tendenza a fondare nel 1893 la Segreteria Olandese del Lavoro, antesignana dell'organizzazione sindacale centrale, primo organo di coordinamento a livello nazionale di tutte le strutture sindacali, indipendentemente dal loro orientamento sindacalista rivoluzionario o meno. Dopo i citati conflitti radicali di inizio secolo, l'equilibrio interno del movimento sindacale si spostò decisamente a favore dei socialisti. Nel 1905-6, 15 unioni nazionali sotto decisa influenza socialista fondarono una Confederazione fortemente centralizzata sul modello della ADGB tedesca. L'istituzione finale di un solido legame fra socialismo politico e sindacale rappresentò il culmine di un lungo processo di consolidamento durante il quale le due organizzazioni avevano scon- 
fitto le rispettive ali sinistre (nei Paesi Bassi, come in Italia, il socialismo politico subì importanti scissioni prima della Prima guerra mondiale). Nel contempo, però, si sviluppavano organizzazioni del lavoro concorrenti di ispirazione cattolica e protestante $^{40}$, che ostacolarono lo sviluppo dei sindacati socialisti e conferirono un carattere frammentato alla rappresentanza del lavoro dipendente $e^{41}$.

Norvegia. La Norvegia occupò un posto piuttosto marginale nella Prima Internazionale; tuttavia la prima organizzazione centrale del movimento sindacale di ispirazione socialista (Den Norske Arbeidenforening) venne fondata assai precocemente, nel 1874 . Anche il partito ebbe un avvio precoce e un rapido consolidamento organizzativo. Una Associazione Socialdemocratica venne fondata nel 1883 sul modello del partito danese (e, attraverso di esso, della SPD tedesca), e due anni dopo si trasformò nel Partito Laburista Norvegese (1885). Probabilmente furono gli antichi e profondi legami con la Danimarca (benché l'unione fra i due paesi fosse terminata nel XIX secolo, sostituita dall'associazione alla corona svedese) a determinare un simile anticipato sviluppo del socialismo politico in un contesto sociale che sembrava ben poco propizio all'azione di classe. $\mathrm{Ci}$ vollero solo due anni perché l'Associazione Socialdemocratica si tramutasse in Den Norske Arbeidenpartei (DNA).

$\grave{E}$ difficile in questa prima fase trovare segni di separazione tra la sfera di azione politica e quella economica. In assenza di una centrale organizzativa sindacale, la funzione di coordinamento delle unioni locali e settoriali era svolta dal partito. Il comitato esecutivo del DNA funzionava come una camera confederale delle samorganisasjon locali, corrispondenti alle Camere del Lavoro. Solo nel 1899-1900 venne costituita una Confederazione Sindacale centrale per assumere queste funzioni e separare formalmente le sfere di azione politica ed economica. La relazione fra partito e sindacato fu sin dall'inizio di tipo ombelicale. Benché il partito avesse preceduto l'organizzazione sindacale centrale, la differenziazione fra i due settori era minima ri-

40 La Federazione Nazionale Cristiana dei Mestieri (protestante) e l'Ufficio Organizzativo dei Mestieri (cattolico) vennero fondati più o meno contemporaneamente alla Federazione Olandese dei Sindacati.

${ }^{41}$ Sui Paesi Bassi si vedano Daalder (1966) e Kossman (1978, specialmente 344349). 
spetto agli altri casi europei. Il partito nacque all'interno delle organizzazioni sindacali che vi aderirono collettivamente e ne costituirono l'infrastruttura organizzativa. Anche nella fase di forte radicalizzazione che precedette e seguì la Prima guerra mondiale (quando il partito per un breve periodo aderì alla Terza Internazionale senza che al suo interno si manifestassero particolari dissensi), tanto il partito quanto il sindacato mantennero una fondamentale unità interna e il monopolio della rappresentanza dei lavoratori ${ }^{42}$.

Svezia. La costituzione del rapporto partito-sindacato nel caso svedese ha modalità simili a quella norvegese, perlomeno nella prospettiva di una ampia comparazione europea. Come in Norvegia, le idee e le organizzazioni specifiche si manifestarono tardivamente e spesso furono «importate». Una volta impiantatesi, tuttavia, non incontrarono grandi difficoltà nell'organizzarsi a livello nazionale. Sia in Svezia che in Norvegia ciò può essere dovuto al fatto che già nella seconda metà del XVIII secolo e durante il XIX erano esistiti ampi e significativi movimenti «popolari» di natura democratica (Movimento della Libera Chiesa, Movimento della temperanza ed altri simili). Essi contribuirono alla precoce diffusione di mentalità liberal-radicali (spesso di coloritura utopica) fra quei lavoratori che si erano organizzati su base educativa o mutualistica attorno alle loro associazioni professionali.

I tentativi di creare un coordinamento nazionale del movimento sindacale iniziarono a Stoccolma nel 1885 con un Comitato Centrale Sindacale che sosteneva un programma apertamente socialista. Immediatamente dopo, i militanti socialisti presero facilmente il controllo dei movimenti sindacali attraverso la loro struttura locale. L'unica alternativa concorrenziale era infatti rappresentata dai liberali (come in Gran Bretagna), e non vi erano importanti contrasti interni al campo socialista. Lo Sweriger Socialdemokratiske Arbitorepartiet (SAP) che venne fondato nel 1889 non aveva di fatto alcun precursore. Per la verità, qualche anno prima (1885) August Palm - un sarto emigrato che in Germania e in Danimarca era venuto in contatto con il socialismo di ispirazione lassalliana - aveva fondato a Malmoe la prima associazione socialista svedese (la Svenske Ar- 
betareförening (ASA)), ma è improprio considerarla un'antesignana del SAP in quanto gli anni seguenti non videro un lento processo di unificazione politica di diverse organizzazioni intorno ad essa. Cinquantuno unioni sindacali erano rappresentate all'atto di fondazione del SAP, fiancheggiate da solo sedici organizzazioni politiche. L'adesione era collettiva e, come in Norvegia, nella prima fase la SAP funzionò come una struttura di collegamento e coordinamento tra le varie federazioni. Nel 1898 venne creata una Confederazione sindacale centrale (LO), ma sin dall'inizio LO e SAP si mossero sotto tutti gli aspetti come un'unica entità. Lo statuto della LO prescriveva l'adesione individuale al partito per i membri delle organizzazioni collettivamente affiliate. Nel 1900 tale clausola (unica in Europa) fu abolita, ma soltanto nel 1908 il contracting-out venne formalmente consentito (benché fortemente sanzionato sul piano sociale). In ogni caso, a quel tempo ancora l' $80 \%$ delle adesioni al SAP erano di tipo collettivo ${ }^{43}$.

Svizzera. Considerata la precoce industrializzazione del paese, non stupisce che in Svizzera le date di fondazione della centrale sindacale (1880) e del partito (1887) siano piuttosto anticipate e che la centralizzazione sindacale preceda quella elettorale. Ciò è invece sorprendente se si tiene conto del fatto che l'intera storia e l'assetto istituzionale dello stato rendevano gli sforzi di centralizzazione poco gratificanti e utili. Le istanze governative centrali erano infatti molto meno importanti che in tutti gli altri casi europei. In effetti, al di là delle date, la realtà del movimento socialista svizzero in ambedue i canali di mobilitazione appare assai modesta. Il movimento operaio svizzero cominciò a darsi un coordinamento nazionale nel 1873, quando venne fondata ad Olten un'assai eterogenea Unione Svizzera dei Lavoratori (composta da rappresentanti della Sezione dell'Internazionale, da alcune unioni sindacali, da alcune società tedesche per l'educazione dei lavoratori e dalla Società Grütli). Dopo un periodo di declino organizzativo durato sino al 1880 , l'Unione dei Lavoratori si sciolse e venne sostituita dall'Union Syndicale Suisse, che voleva essere un'organizzazione «esclusivamente sindacale sulla base dei principii socialisti». La Confederazione Sindacale Svizzera era però assai debole (12 sezioni e

${ }^{43}$ Per la Svezia, cfr. Galenson (1952). 
133 membri) ed ebbe uno sviluppo lento (nel 1885 era ancora a 23 sezioni e 593 membri). Molto più importante era la Società Grütli, che contava a quel tempo su 6.000 aderenti. Fu in effetti proprio la Società Grütli a creare nel 1886 i fondi di riserva iniziali necessari a finanziare gli scioperi sindacali, che rappresentarono un importante incentivo per l'adesione di altre federazioni all'USS ${ }^{44}$. Ancora nel decennio 1890-1900 gran parte delle energie dell'USS erano dedicate al coordinamento delle alquanto disparate organizzazioni, comprese alcune federazioni professionali, unioni operaie locali (che avevano scopi sindacali ma includevano membri del partito socialista e società mutualistiche) e strutture sindacali isolate. La precoce fondazione dunque, più che un risultato conclusivo, fu soltanto l'inizio dello sviluppo organizzativo e della centralizzazione dei sindacati.

Il partito si formò nel 1888, 8 anni dopo la confederazione sindacale centrale e dopo due tentativi falliti nel 1870 e nel 1880. Rimase organizzativamente debole sino alla fusione con la Società Grütli nel 1901. Sperando di rafforzarsi grazie all'associazione con i sindacati, nel 1891 abolì l'adesione individuale e passò a quella collettiva, ma nel 1916 tornò sui suoi passi. Fra il 1888 e il 1916, malgrado tutti gli sforzi compiuti, il partito avrebbe potuto essere descritto come una federazione di sezioni locali che si basava sul sostegno di alcune grandi Unioni (soprattutto quelle della metallurgia e dell'edilizia). Il dilemma centralizzazione/cantonalizzazione fu sin dall'inizio una delle sue massime preoccupazioni, e tale rimase per l'intero corso della sua storia. Le barriere linguistiche e le radici quasi esclusivamente circoscritte alla Svizzera tedesca ${ }^{45}$ rendevano difficile centralizzare un'organizzazione le cui sezioni cantonali si trovavano a confronto con sistemi di partito, possibilità di alleanza e strutture di potere diversi. Anche se le sue organizzazioni federali erano più importanti di quelle locali a paragone degli altri

44 In origine la Società Grütli era un'organizzazione «radicale» (nel senso svizzero del termine) che si collocava politicamente fra il radicalismo svizzero e il socialismo moderato, senza l'obiettivo di creare coscienza o azione di classe. Paradossalmente - dato l'importante ruolo da essa svolto nel primo movimento socialista - alcuni storici la considerano un fattore che ritardò e ostacolò la formazione di un partito socialista. Cfr. Gass (1988).

${ }^{45}$ La parte di lingua tedesca del paese offriva condizioni più favorevoli alla mobilitazione socialista: una più alta industrializzazione; l'influenza politica di militanti e leaders socialisti tedeschi emigrati; l'assenza dell'influenza dello storico Partito Radicale. Si veda in proposito Vuilleumier (1988). 
partiti svizzeri, il livello di coordinamento e di autorità centrale raggiunto era modesto a confronto con quello di altri partiti socialisti europei.

Alla frammentazione territoriale delle due istanze va aggiunta la concorrenza dei sindacati cattolici, che iniziò nel 1901. La frammentazione della rappresentanza dei lavoratori si intensificò all'inizio del secolo (Conferenza di Basilea del 1906), quando la confederazione sindacale di simpatie socialiste (SGB-USS) decise di abbandonare il principio di neutralità politica e religiosa (codificato nel 1902) a favore di una piattaforma basata sulla lotta di classe ${ }^{46}$.

Gran Bretagna. Quello britannico viene abitualmente considerato un caso evidente di mobilitazione organizzativa precoce nel canale corporato degli interessi e di mobilitazione politica tarda e derivata. Significativi settori sindacali hanno origini che risalgono al $1850 \mathrm{o}$ addirittura più remote. Il processo che portò al loro coordinamento a livello centrale nel Trade Union Congress fu pertanto continuo e graduale, non determinato da uno stimolo o da un coordinamento politico esterno. La prima struttura sindacale nazionale in Gran Bretagna venne costituita già nel 1868 e da allora in poi si è riunita ogni anno. A quel tempo i sindacati affiliati reclutavano già all'incirca 120.000 aderenti ${ }^{47}$.

Il British Labour Party, fondato ufficialmente nel 1906, ma in realtà concepito nel 1900, deve la sua nascita all'insoddisfazione espressa dalle Trade Unions nel 1896 nei confronti dei Liberali. E difficile individuarne degli autentici predecessori. Effettivamente una Social Democratic Federation, marxista, venne fondata nel 1884, ma rimase estremamente debole. L'Independent Labour Party fu costituito nel 1893, ed era meno ortodosso ideologicamente e più importante dal punto di vista numerico. Le Società Fabiane esistevano da molto tempo. Tutte queste forze si riunirono per iniziativa del TUC in uno speciale congresso di tutte le «organizzazioni cooperative, socialiste, sindacali e operaie», ma è ovvio che fu il cruciale impulso del TUC a creare di fatto il partito ${ }^{48}$. Il Labour Representation Committee

46 Sulle origini del movimento socialista svizzero vedi Balthasar, Gruner e Hirter (1988), Garbani e Schmid (1980), Reymond-Sauvain (1966).

47 Pelling (1969).

${ }^{48}$ Cfr. Pelling $(1965,205)$. 
creato nel 1900 era, in senso stretto, una coalizione di organizzazioni e non un'istituzione autonoma. La vera separazione organizzativa potrebbe essere collocata cronologicamente nel 1919, quando il partito si aprì all'adesione individuale.

Il rapporto originario fra sindacato e partito non fu però di pura e semplice dipendenza del secondo dal primo. Il partito laburista si trasformò rapidamente in un'inusuale coalizione di forze, qualcosa di simile al primo partito socialista belga. Le Trade Unions svolsero una funzione predominante attraverso l'affiliazione collettiva, ma non «colonizzarono» mai il partito come accadde in Irlanda. La spiegazione va cercata in un certo numero di circostanze e caratteristiche del sindacalismo britannico: la sua sensazione di forza, autonomia e consapevolezza; la forte preoccupazione per l'integrità organizzativa; la priorità costante ai problemi industriali, e, infine, una certa sensibilità alle esigenze del partito e un forte senso di costituzionalità. Tutto ciò lasciò sempre al Partito Laburista un margine di manovra piuttosto ampio. Per molti versi, pur appartenendo al medesimo genus di relazioni, la differenza con l'esperienza norvegese e svedese risiede in un più alto grado di divisione del lavoro e in un'interpenetrazione meno profonda.

Questa ricognizione storica paese per paese era necessaria per giungere ad una percezione comparata del consolidamento organizzativo e delle relazioni fra socialismo sindacale e politico. Nelle tabb. 2 e 3 tale esercizio comparato viene sintetizzato nei termini dello schema concettuale discusso in apertura del saggio. Nella tab. 2 è suggerita per ciascun paese una data che si riferisce alla prima spinta verso la centralizzazione nazionale dei movimenti sindacali e del movimento partitico/politico. In altre colonne sono riportati i dati corrispondenti alla avvenuta formazione di una confederazione sindacale e di un partito socialista organizzati sul piano nazionale. Laddove possibile, viene indicata fra parentesi la lunghezza del processo di consolidamento organizzativo centrale in entrambi $i$ canali. L'informazione contenuta allo stato grezzo nella tab. 2 può essere analizzata lungo tre dimensioni: 1) la sequenza del processo, cioè quale dei due settori, politico o economico, si è centralizzato per primo; 2) il timing del processo, cioè se la centralizzazione nella sfera politica ed economica sia stata, comparativamente, precoce o tardiva; e 3) la durata del processo, cioè la sua natura più rapida o protratta. Questa descrizione, basata su punti di soglia, 
$\mathrm{T}_{\mathrm{AB}}$ 2. Fondazione dei partiti e dei sindacati socialisti

\begin{tabular}{|c|c|c|c|c|c|c|c|c|}
\hline Paese & $\begin{array}{l}\text { Inizio fase di } \\
\text { centralizzazione } \\
\text { nazionale del } \\
\text { sindacato }\end{array}$ & & $\begin{array}{l}\text { Fondazione } \\
\text { del centro } \\
\text { sindacale } \\
\text { nazionale }\end{array}$ & & & $\begin{array}{l}\text { Inizio fase di } \\
\text { centralizzazione } \\
\text { nazionale del } \\
\text { partito }\end{array}$ & $\begin{array}{l}\text { Fondazione } \\
\text { del partito } \\
\text { nazionale }\end{array}$ & \\
\hline Austria & 1867 & & 1893 & (26 anni) & & 1874 & 1889 & (15 anni) \\
\hline Belgio & $1857-60$ & & 1898 & $(38-41)$ & & 1864 & 1885 & $(21)$ \\
\hline Danimarca & $\sim 1871$ & & 1898 & $(28)$ & & 1871 & $1876-78$ & $(5-7)$ \\
\hline Finlandia & $1896-1900$ & & 1907 & $(11-7)$ & & 1893 & 1899 & (6) \\
\hline Francia & 1886 & $(1895)$ & 1902 & (16) & & 1880 & 1905 & (25) \\
\hline Germania & 1868 & & 1875 & (7) & & $1863-64$ & 1875 & (12) \\
\hline Irlanda & $(1880)$ & & 1894 & (14) & & 1912 & 1922.30 & $(10-18)$ \\
\hline Italia & $(1880)$ & & 1906 & $(20-26)$ & & $\sim 1880$ & 1892 & (10) \\
\hline Paesi Bassi & 1893 & & $1905-6$ & $(12)$ & & 1881 & 1894 & (13) \\
\hline Norvegia & 1874 & & 1899 & $(25)$ & & 1885 & 1887 & (2) \\
\hline Svezia & 1885 & & 1898 & (13) & & - & 1889 & $(0)$ \\
\hline Svizzera & 1873 & & 1880 & (7) & $(1870)$ & 1880 & 1887 & $(7-17)$ \\
\hline Gran Bretagna & - & & 1868 & & & (1884?-1893?) & $1900-06$ & $(6-20)$ \\
\hline
\end{tabular}


TAB. 3. Modelli di consolidamento organizzativo del partito e del sindacato (1880-1940)

\begin{tabular}{|c|c|c|c|c|c|c|c|c|c|}
\hline \multirow[t]{3}{*}{ paese } & \multirow[t]{3}{*}{ sequenza } & \multirow{2}{*}{\multicolumn{2}{|c|}{ timing }} & \multirow{2}{*}{\multicolumn{2}{|c|}{ durata }} & \multirow[t]{3}{*}{ legame } & \multicolumn{3}{|c|}{ modo di rappresentanza } \\
\hline & & & & & & & \multicolumn{2}{|c|}{ monopolio della rappresentanza } & \multirow[t]{2}{*}{ tipo } \\
\hline & & $\begin{array}{l}\text { canale } \\
\text { corporato }\end{array}$ & $\begin{array}{l}\text { canale } \\
\text { elettor. }\end{array}$ & $\begin{array}{l}\text { canale } \\
\text { corporato }\end{array}$ & $\begin{array}{l}\text { canale } \\
\text { elettor. }\end{array}$ & & $\begin{array}{l}\text { canale } \\
\text { corporato }\end{array}$ & $\begin{array}{l}\text { canale } \\
\text { elettorale }\end{array}$ & \\
\hline Austria & parallela & interm. & interm. & lunga & lunga & interdipen. & SI (?) & SI (?) & $\begin{array}{l}\text { corporato/ } \\
\text { framm. segment. }\end{array}$ \\
\hline Danimarca & par.prima & interm. & precoce & lunga & breve & interdipen. & SI & SI & corporato \\
\hline Finlandia & parallela & interm. & tardo & breve & breve & $\begin{array}{l}\text { dipendenza/ } \\
\text { interdipen. }\end{array}$ & SI & No & framm. ideol. \\
\hline Francia & parallela & tardo & tardo & lunga & lunga & $\begin{array}{l}\text { contingente/ } \\
\text { demand group }\end{array}$ & No & No & framm. ideol. \\
\hline Germania & parallela & precoce & precoce & breve & med. & $\begin{array}{l}\text { dipendenzal } \\
\text { interdipen. }\end{array}$ & No & No & $\begin{array}{l}\text { frammentato } \\
\text { ideol. \& segm. }\end{array}$ \\
\hline Irlanda & sind.prima & interm. & tardo & med. & lunga & dipendenza & No & No & framm. ideol. \\
\hline Paesi Bassi & par.prima & tardo & tardo & med. & med. & interdipen. & No & No & framm. segm. \\
\hline Norvegia & par.prima & interm. & interm. & lunga & breve & interdipen. & SI & SI & corporato \\
\hline Svezia & par.prima & interm. & interm. & med. & breve & interdipen. & SI & SI & corporato \\
\hline Svizzera & sind.prima & precoce & interm. & breve & $\begin{array}{l}\text { breve/ } \\
\text { med. }\end{array}$ & contingente & No & No & $\begin{array}{l}\text { framm. ideol./ } \\
\text { segm./territ. }\end{array}$ \\
\hline Gr. Bret. & sind.prima & precoce & tardo & breve & lunga & $\begin{array}{l}\text { dipendenza/ } \\
\text { interdipen. }\end{array}$ & SI & SI & corporato \\
\hline
\end{tabular}


non offre un quadro completo se non viene integrata da aspetti qualitativi riguardanti la natura del rapporto fra le organizzazioni attive nei due canali. Sequenza, timing e durata del processo devono essere integrati con 4) i tipi di legame partito/sindacato e 5) i modi di rappresentanza prevalenti (cfr. la tab. 1). Nella tab. 3 sono riportate queste cinque caratteristiche, che sono poi discusse nei paragrafi che seguono. Ė essenziale ricordare che le caratterizzazioni delle esperienze nazionali riportate nella tab. 3 sono il risultato di un confronto tra i nostri tredici casi.

\section{Sequenza}

Nella maggioranza dei casi, la centralizzazione dell'organizzazione politica è avvenuta prima che un simile processo si verificasse nel canale corporato: la Danimarca e il Belgio sono i casi più chiari di tale sequenza, seguiti, con ritardi minori, dai casi dei Paesi Bassi, dell'Italia, della Norvegia e della Svezia. In Germania, Austria, Finlandia e Francia i processi sono stati abbastanza paralleli, mentre in Svizzera e soprattutto in Gran Bretagna e in Irlanda la centralizzazione nel settore sindacale ha preceduto quella nell'ambito politico. In questi dati vi è un elemento paradossale. Non vi è dubbio che in Europa occidentale il processo di mobilitazione operaia nel canale corporato precede largamente $i$ tentativi di mobilitazione politica in quello elettorale. Da ciò deriva l'immagine di un «travaso» politico di una risposta fondamentalmente economica. Tuttavia, malgrado una mobilitazione corporata più precoce di quella elettorale, in quasi tutti i casi l'effettiva centralizzazione organizzativa di una confederazione nazionale dei sindacati si è verificata dopo che era stato costituito un partito politico a livello nazionale.

In questo caso, le spiegazioni che si rifanno al più o meno avanzato sviluppo industriale (a causa dell'influenza esercitata dal caso britannico di industrializzazione precoce e anticipato sviluppo sindacale) non funzionano. Mentre un modello ritardato di industrializzazione può spiegare il tardivo sviluppo del sindacato in un dato paese rispetto ad altri, lo stesso fattore non è altrettanto convincente nello spiegare il ritardato sviluppo organizzativo sindacale rispetto a quello elettorale nello stesso paese. Altri importanti fattori sono che: 1) la necessità di centralizzazione veniva percepita più facilmente nella sfera politica; 2) la trasmissione transnazionale e la diffusione di forme 
politico-organizzative era più agevole nella sfera politica; 3 ) c'erano importanti differenze intrinseche nelle opportunità di mobilitazione di un identico gruppo di sostenitori nei due diversi canali.

Nei loro sforzi originari per mobilitare politicamente cittadini in precedenza inattivi, gli attivisti e i partiti socialisti dovevano coinvolgere gli individui dal punto di vista emotivo rispetto ad ideali astratti, categorie astratte di individui e relazioni impersonali. Dovevano essere sollecitati sentimenti di solidarietà fra individui fisicamente e socialmente distanti. Dovevano essere indeboliti i tradizionali legami affettivi dei singoli con altri gruppi primari o territoriali più diretti. In ogni caso, essi dovevano indurre il loro potenziale elettorato ad agire in contrasto con le norme e i ruoli dominanti nel suo ambiente geo-sociale $\mathrm{e}$, in genere, con l'autorità della gerarchia sociale a livello loca$\mathrm{le}^{49}$.

Paragonata a queste difficoltà della mobilitazione elettorale e partitica, la mobilitazione sindacale aveva il vantaggio di fare riferimento sul posto di lavoro alle caratteristiche e agli interessi più diretti e concreti del gruppo di riferimento e ad idee meno astratte. L'interesse funzionale-economico diretto e le esperienze di destino comune venivano percepite più facilmente dei più vasti interessi politici nazionali. Il «nemico» di fabbrica era più vicino della «classe capitalista» e dello stato. La percezione del fatto che il destino individuale e collettivo poteva essere influenzato da un lontano apparato decisionale politico esigeva una maggiore educazione politica e sofisticazione intellettuale. Il reclutamento e la mobilitazione corporata si svolgevano in un ambiente sociale molto più omogeneo di quello delle attività partitiche ed elettorali ${ }^{50}$. Non stupisce, perciò, che la prima mobilitazione dei lavoratori si sia svolta nelle società operaie e di mutuo soccorso, nelle cooperative e nei sindacati, piuttosto che in associazioni con un più pronunciato carattere politico e nei partiti.

\footnotetext{
49 Si noti la differenza con la mobilitazione religiosa: anche in questo caso l'enfasi viene posta su ideali e gruppi astratti e spesso in contrasto con la struttura di potere locale e centrale, ma essa si fonda su identità ben definite e su autorità che offrono un senso di protezione dalle altre autorità «esterne». Non così accade con la mobilitazione di classe.

so Sull'importanza dell'omogeneità del contesto sociale per la partecipazione cfr. Rokkan (1970, 13-45).
} 
Cionondimeno, quando si prende in considerazione il problema del coordinamento e del consolidamento organizzativo nazionale - invece di quello della prima mobilitazione - alcuni di questi elementi di vantaggio si affievoliscono e si trasformano in svantaggi. I sindacati dovettero affrontare alcune difficoltà aggiuntive che spiegano perché la loro organizzazione cominciò molto prima di quella partitico/politica a livello locale ma si concluse più tardi a livello centrale. Per consolidarsi, le confederazioni nazionali avevano bisogno - non meno dei partiti politici - di affermare una crescente autorità e un maggior coordinamento sulle organizzazioni locali, ovvero di aver ragione della frammentazione territoriale (camere di commercio e simili precoci forme territoriali di organizzazione). Mentre per i partiti politici questo processo era facilitato dalla ovvia centralizzazione del potere e del processo decisionale negli esecutivi nazionali e nei parlamenti, niente di simile favoriva l'organizzazione centrale dei sindacati. Le politiche potevano essere decise al centro, ma gli interessi immediati degli aderenti avevano più evidentemente a che fare con il livello di fabbrica o, al massimo, di settore produttivo. Come nel caso del partito, era necessario aggiungere un elemento di più astratta solidarietà per incoraggiare lo sviluppo centrale e confederale. È naturale che spesso questo stimolo sia stato prodotto dall'organizzazione politica più necessariamente orientata verso il centro nella sua azione. Inoltre le confederazioni centrali dovevano risolvere problemi che, in quanto tali, erano inesistenti per il partito politico: a) l'integrazione di diverse tradizioni di mestiere, qualifiche e figure professionali in un'unica unione sindacale di un determinato settore; b) l'integrazione di varie unioni settoriali in un'unica confederazione nazionale. In altre parole, le differenze di status all'interno della classe operaia erano meno importanti e meno dannose per il partito che per il sindacato, che era sin dall'inizio altamente stratificato per mestieri e qualifiche professionali. Nella sfera politica esisteva un'area ideologica di eguaglianza fra gli aderenti che era assai più difficile da raggiungere in un mercato del lavoro ancora fortemente stratificato e segmentato ${ }^{51}$. Era difficile integrare il primo sindacalismo di mestiere in più ampi movimenti sindacali; così come lo era vincere la resistenza

51 Sul rilievo delle «aree di eguaglianza» nell'incoraggiamento della partecipazione politica cfr. Pizzorno (1966). 
degli operai (e dei sindacati) specializzati a ulteriori ondate di espansione organizzativa in settori meno qualificati della forzalavoro. Ciò può spiegare perché storicamente la mobilitazione sindacale preceda qualla elettorale-partitica, ma il suo coordinamento e consolidamento organizzativo nazionale si verifichi dopo quello dei partiti e spesso sotto gli auspici di questi ultimi.

\section{Timing}

Per quanto concerne il timing, il primo aspetto da mettere in rilievo è l'assai limitata corrispondenza fra la precocità o il ritardo del consolidamento organizzativo centrale nell'uno o nell'altro canale. Nel canale corporato un coordinamento nazionale precoce caratterizza l'esperienza di Gran Bretagna, Germania e Svizzera, tutti casi in cui tale processo era già stato realizzato prima del decennio 1880-1890. All'altro estremo, Italia, Paesi Bassi e Francia rappresentano casi nei quali l'organizzazione centrale nazionale venne raggiunta nel primo decennio del XX secolo. Tutti gli altri casi vedono l'istituzione di confederazioni nazionali centralizzate nell'ultimo decennio del XIX secolo.

La situazione è diversa per le organizzazioni politiche. In Germania e in Danimarca la costituzione delle istanze centrali dei partiti nazionali avviene già negli anni settanta. In Austria, Belgio, Norvegia, Svezia e Svizzera negli anni ottanta; in Finlandia, Italia e Paesi Bassi negli anni novanta, e, infine, in Francia, Gran Bretagna e Irlanda, l'organizzazione politica socialista si costituisce solo nel primo quarto del XX secolo. Germania e Francia rappresentano casi omogenei di consolidamento organizzativo rispettivamente molto precoce e molto tardivo in ambedue i canali. L'esperienza irlandese si avvicina a quella della Francia; quella svizzera a quella della Germania. Tutti gli altri paesi si situano tra questi casi estremi. Italia e Paesi Bassi tendono ad approssimarsi al modello della Francia come «ritardatari» in entrambi i canali. La Gran Bretagna è il caso più netto di biforcazione totale nello sviluppo dei due canali: il consolidamento organizzativo nel canale corporato è tanto precoce quanto tardivo è il corrispondente sviluppo politico. La Danimarca è il caso più chiaro di situazione inversa: la formazione del partito nazionale è straordinariamente precoce se comparata con la relativamente tarda organizzazione della centrale sindacale. 


\section{Durata}

L'aspetto relativo alla durata del processo di consolidamento organizzativo è il più difficile da valutare. Ogni stima dipende dalla definizione del punto di partenza del consolidamento politico e sindacale nazionale; una scelta difficile e soggetta a critiche. Limiteremo pertanto queste considerazioni a quegli aspetti che appaiono più evidenti e importanti.

In termini di durata del processo di consolidamento organizzativo ( $\mathrm{e}$ indipendentemente dal fatto se tale processo sia stato precoce o tardivo in termini comparativi o sia stato iniziato dal partito o dal sindacato), la caratteristica più interessante è la netta differenza fra paesi cattolici e protestanti. I paesi omogeneamente protestanti mostrano un processo di centralizzazione politico più breve e apparentemente meno problematico. In Svezia, Norvegia, Finlandia e Danimarca esso occupa solo pochi anni ( $\mathrm{da} 0$ a 7 ); il Regno Unito, dove il processo è condotto dai sindacati, è un caso più difficile da classificare. Nei paesi a religione mista e in quelli omogeneamente cattolici il processo appare più lungo, più problematico. Germania e Paesi Bassi hanno intervalli temporali intermedi (12-13 anni circa); paesi cattolici come Francia, Belgio, Austria e Irlanda ne hanno di più lunghi sia nel canale corporato che in quello elettorale. La differenza può essere dovuta a un più forte conflitto ideologico interno e a una maggiore competizione fra organizzazioni socialiste rivali, e anche alla presenza di associazioni e sindacati non-socialisti egualmente forti. Non tutti i casi si adattano così bene allo schema; la Svizzera è un paese misto dal punto di vista religioso nel quale l'unificazione politica - considerando il 1880 come punto di partenza - si svolge rapidamente. In Italia il socialismo politico pare aver avuto meno problemi che negli altri paesi cattolici, forse grazie al fatto che la mobilitazione politica concorrenziale dei cattolici fu rinviata dall'atteggiamento intransigente del Vaticano.

\section{Legame}

Nell'esperienza del movimento socialista il legame prevalente tra $\mathrm{i}$ canali ha carattere di interdipendenza, con organizzazioni parallele e leaderships sovrapposte. Se la situazione non è stata di 
questo tipo sin dal primo momento, ha teso a diventarlo con l'andar del tempo. In casi come quelli della Germania, della Finlandia, della Gran Bretagna e dell'Irlanda una fase iniziale di dipendenza (dipendenza dei sindacati nei confronti del personale e della guida politica del partito nei primi due casi; dipendenza del partito negli ultimi due) si è progressivamente trasformata nel classico modello di interdipendenza. Il caso irlandese dovrebbe comunque essere differenziato da quello britannico, dal momento che la posizione di dipendenza si protrasse a lungo e faticò ad essere superata sino alla Seconda guerra mondiale.

Abbiamo classificato il legame nei casi francese, italiano e svizzero come «contingente», e questa definizione richiede forse qualche ulteriore spiegazione. In tutti questi casi - pur con importanti differenze - le relazioni tra socialismo politico e sindacale si sono dimostrate organizzativamente più deboli, meno stabili, più conflittuali e con una divisione del lavoro meno netta. La situazione francese è la più pura da questo punto di vista. Basta ricordare le numerose occasioni in cui socialismo politico e sindacale hanno seguito linee in contrasto; in cui il partito politico è stato costretto ad affrontare azioni sindacali autonome e non preventivamente concordate; la continuamente riaffermata indipendenza del sindacato rispetto alla politica. In effetti, nel periodo da noi considerato più di una volta il movimento sindacale francese è stato tentato di adottare una posizione di semplice «gruppo-cliente» rispetto al partito. La situazione italiana prima del fascismo non è molto diversa, o quantomeno ci sembra più simile a quella francese che a quella dei casi di interdipendenza. Il caso svizzero è di natura differente. Qui la debolezza organizzativa e la scarsa centralizzazione di entrambe le organizzazioni hanno sempre significato differenza delle posizioni politiche e sindacali sul territorio nazionale e debolissimo coordinamento.

\section{Modo di rappresentanza}

La natura del legame fra organizzazione centrale politica e sindacale deve poi essere collocata nel contesto del più ampio sistema di rappresentanza degli interessi nel sistema politico. La modalità corporata o frammentata indica la presenza o l'assenza di una relazione uno-a-uno nella rappresentanza di ambedue i canali (si veda la tab. 1 e la sua discussione). Un'organizzazione 
sindacale di ispirazione socialista può avere una forte interdipendenza con il partito socialista, ma non essere in grado di rivendicare la completa rappresentanza del movimento sindacale organizzato. Sul versante politico, la frammentazione ideologica o segmentata o territoriale può dar vita ad organizzazioni in concorrenza per la rappresentanza politica del mondo del lavoro. Nel canale corporato questo problema può essere operazionalizzato in termini di quanto il lavoro dipendente sindacalizzato sia effettivamente rappresentato dalla principale confederazione socialista $e$, in secondo luogo e subordinatamente, se tale confederazione sia più o meno internamente divisa. Nel canale politico il problema è se la rappresentanza politica del mondo del lavoro sia rivendicata da un unico ed unito partito politico oppure da una varietà di formazioni politiche.

Nella maggior parte dei casi, la frammentazione della rappresentanza ha un andamento parallelo in entrambi i canali. La Finlandia è probabilmente l'unico caso di un movimento sindacale socialista unificato che ha come punto di riferimento politico due partiti politici: socialista e comunista. La precoce mobilitazione di sindacati religiosi ha causato la mancanza di un monopolio della rappresentanza corporata nei Paesi Bassi, in Belgio e Svizzera. Nei Paesi Bassi e in Italia il movimento politico socialista era già diviso sul piano ideologico e anche organizzativo prima della Prima guerra mondiale. In Germania lo è diventato a partire dal periodo bellico. In Francia era ideologicamente diviso prima della Prima guerra mondiale e si è diviso anche organizzativamente negli anni venti e trenta. La divisione politica della sinistra è stata molto più occasionale e meno importante negli altri paesi.

Rispetto al modo di rappresentanza, il caso che solleva maggiori problemi di classificazione è quello dell'Austria, dove vennero precocemente fondati sia un partito che una centrale sindacale di ispirazione cattolica in diretta competizione con le strutture socialiste, mentre all'interno della sinistra non era presente nessuna significativa frammentazione organizzativa. La sovrapposizione dei cleavages religioso e di classe ha però prevalso sulla loro intersecazione, col risultato che l'allineamento di classe ha teso a coincidere con quello confessionale molto più che in altri paesi dove pure erano presenti organizzazioni elettorali e sindacali di ispirazione religiosa. Saremmo perciò tentati di assimilare l'esperienza austriaca più alla modalità corporata di rappresentanza che a quella frammentata. 
Come accennato in precedenza, la natura della frammentazione (ideologica, segmentata, territoriale o mista) è meno importante ai fini dell'argomento svolto in questa sede, e non verrà presa in considerazione in questo saggio. Tale distinzione diventerà molto importante dopo il 1945, specialmente in casi come quelli della Francia e dell'Italia, che videro la nascita di varie confederazioni sindacali «secolari». La situazione successiva al 1945 vede del resto parecchi altri cambiamenti, con il ritorno, per esempio, a situazioni di dipendenza dei sindacati nel caso delle confederazioni a guida comunista.

\section{Mobilitazione degli aderenti}

In questa sezione l'attenzione si sposta dai modelli di consolidamento organizzativo ai livelli di mobilitazione degli aderenti. L'obiettivo generale è descrivere le differenze in chiave transnazionale nei tassi e nei livelli di mobilitazione sindacale, partitica ed elettorale. Più precisamente, ci interessa verificare 1) se le differenze nell'originario consolidamento organizzativo centrale (sequenza, timing, durata, legame, modo di rappresentanza) abbiano influenzato la successiva capacità di mobilitazione degli aderenti; 2) se le agenzie operanti nella sfera economica siano state più pronte nel sollecitare la mobilitazione di quelle politiche o viceversa; cioè, se $i$ cittadini mobilitati nella politica elettorale fossero già organizzati nel canale dei gruppi corporati; e 3) se il rapporto tra i livelli di densità organizzativa nel settore sindacale, partitico ed elettorale configuri modelli diversi di mobilitazione socialista.

Abbiamo raccolto da molteplici fonti ${ }^{52}$ i dati sull'andamento

52 Le fonti elettorali sono documentate in Bartolini e Mair (1990, appendice 1). Le fonti per gli iscritti ai partiti sono documentate in Bartolini (1983, 204 e 216-219). Tali dati sono aggionati al 1990 grazie al progetto di ricerca sulle organizzazioni di partito diretto da Richard Katz e Peter Mair; vedi Katz e Mair (1992). In aggiunta a queste fonti, per un certo numero di piccoli partiti comunisti ulteriori informazioni sono tratte da Sworatowski (1973). Le cifre relative agli aderenti alle confederazioni sindacali vengono da due fonti principali: Visser (1987) e Bain e Price (1976). Nessuna di esse copre tutti i paesi inclusi in questo saggio. In Visser (1992) sono disponibili ulteriori dati relativi a Irlanda, Finlandia e Belgio. Altre informazioni aggiuntive sono state tratte da varie fonti: per la Finlandia, Työministeriö (1990), resomi disponibile da Jelle Visser, e Suviranta (1987); per l'Irlanda, Roberts (1958-59, 95), MacCarthy (1977, 622), Roche (1990; 1992); per la Svizzera fra il 1881 e il 1913, Balthasar, Gruner e Hirter (1988, 66-68, $155,158)$. 
storico del 1) numero totale degli iscritti ai sindacati e numero totale degli iscritti ai sindacati di ispirazione socialista e comunista; 2) numero totale degli iscritti ai partiti socialisti e comunisti; 3) numero totale di voti ottenuti dai partiti della sinistra di classe alle elezioni ${ }^{53}$. Le cifre relative agli aderenti ai sindacati sono state quindi conteggiate a) in percentuale della forza-lavoro dipendente allo scopo di ottenere una misura comparativa dei livelli di sindacalizzazione nei diversi paesi; b) in percentuale degli aventi diritto di voto allo scopo di comparare direttamente livelli di mobilitazione sindacale ed elettorale; c) in percentuale sul voto complessivo della sinistra in ciascun paese ed elezione allo scopo di ottenere informazioni sulla densità della rete organizzativa costruita attorno alla frattura di classe. Anche le cifre degli iscritti ai partiti sono state calcolate in percentuale sull'elettorato e sui voti di sinistra per ragioni analoghe. Questo produce la seguente lista di indicatori di mobilitazione:

mobilitazione sindacale

TUD: iscritti ai sindacati in percentuale della forza-lavoro dipendente;

LTUD: iscritti ai sindacati di sinistra in percentuale della forzalavoro dipendente;

LTUE: iscritti ai sindacati di sinistra in percentuale dell'elettorato;

LTUV: iscritti ai sindacati di sinistra in percentuale del numero di voti dei partiti della sinistra;

mobilitazione partitica

PD1: il totale degli iscritti ai partiti socialisti e comunisti in percentuale dell'elettorato;

PD2: il totale degli iscritti ai partiti socialisti e comunisti in percentuale del numero totale dei voti di sinistra;

mobilitazione elettorale

TLV: i voti combinati di tutti i partiti della sinistra di classe in percentuale dell'elettorato.

Questi indicatori sono stati calcolati su base annua. In que-

33 Una lista dei partiti che sono stati inclusi nella sinistra storica di classe è in Bartolini e Mair $(1990,314)$. 
sto saggio saranno analizzati per media decennale e anno di elezione. Prima di passare all'analisi è necessario un chiarimento. I livelli e le percentuali di mobilitazione sindacale, partitica ed elettorale possono dipendere da aspetti relativi all'ambiente entro il quale operano i movimenti socialisti delle singole nazioni, e che come tali si collocano al di fuori dei ristretti scopi di questo saggio. La capacità di mobilitazione di partiti e gruppi è influenzata dalla natura più o meno chiusa del canale nel quale agiscono. La mobilitazione elettorale esige il superamento delle soglie di legittimazione e di incorporazione. La mobilitazione corporata esige la garanzia dei diritti di associazione e azione collettiva. La concessione del diritto di voto e le libertà associative sono perciò variabili intervenienti decisive fra il consolidamento organizzativo e la mobilitazione politica ${ }^{54}$. Nella discussione che segue, queste variabili sono considerate in modo parziale e non sistematico. Esse costituiscono l'oggetto specifico di altre parti di un più ampio progetto riguardante la mobilitazione della sinistra di classe in Europa.

\section{Consolidamento organizzativo e mobilitazione}

Per analizzare se le diverse modalità di consolidamento organizzativo centrale abbiano influenzato i livelli delle tre forme di mobilitazione socialista, è necessario ricollegare quest'ultima alla classificazione della tab. 3. La tab. 4 riporta i livelli medi dei tre tipi di mobilitazione (LTUD; PD1; TLV) a seconda delle modalità di consolidamento organizzativo. I casi sono le elezioni nazionali del periodo $1900-1940$, quando tutti i paesi han-

54 In un articolo recente Ebbinghaus $(1992,5-6)$ ha tracciato un interessante parallelismo fra barriere nel canale partitico-elettorale e barriere nel canale corporato. Per mobilitare sostegno nel canale corporato, i sindacati dovevano superare soglie di 1) associazione, 2) azione collettiva (sciopero), 3) contrattazione (riconoscimento come partners della contrattazione collettiva), 4) partecipazione (coinvolgimento nella formulazione e nella gestione delle politiche economiche). Egli suggerisce percettivamente che la relazione che è prevalsa fra partiti e sindacati - quella che qui abbiamo chiamato «legame» e «modo di rappresentanza» - è dipesa da fattori connessi alla sequenza temporale del superamento delle soglie, ed avanza le seguenti ipotesi: 1) quanto più e quanto prima «i due percorsi sono stati separati, tanto più dobbiamo aspettarci che il partito e il sindacato siano ben differenziati e scarsamente dipendenti; 2) se il canale politico rimane chiuso più a lungo, dobbiamo aspettarci una politicizzazione delle organizzazioni nel canale corporato. Nel caso inverso, i sindacati procederanno ad alleanze politiche». 
ТАВ. 4. Consolidamento organizzativo e livelli di mobilitazione politica

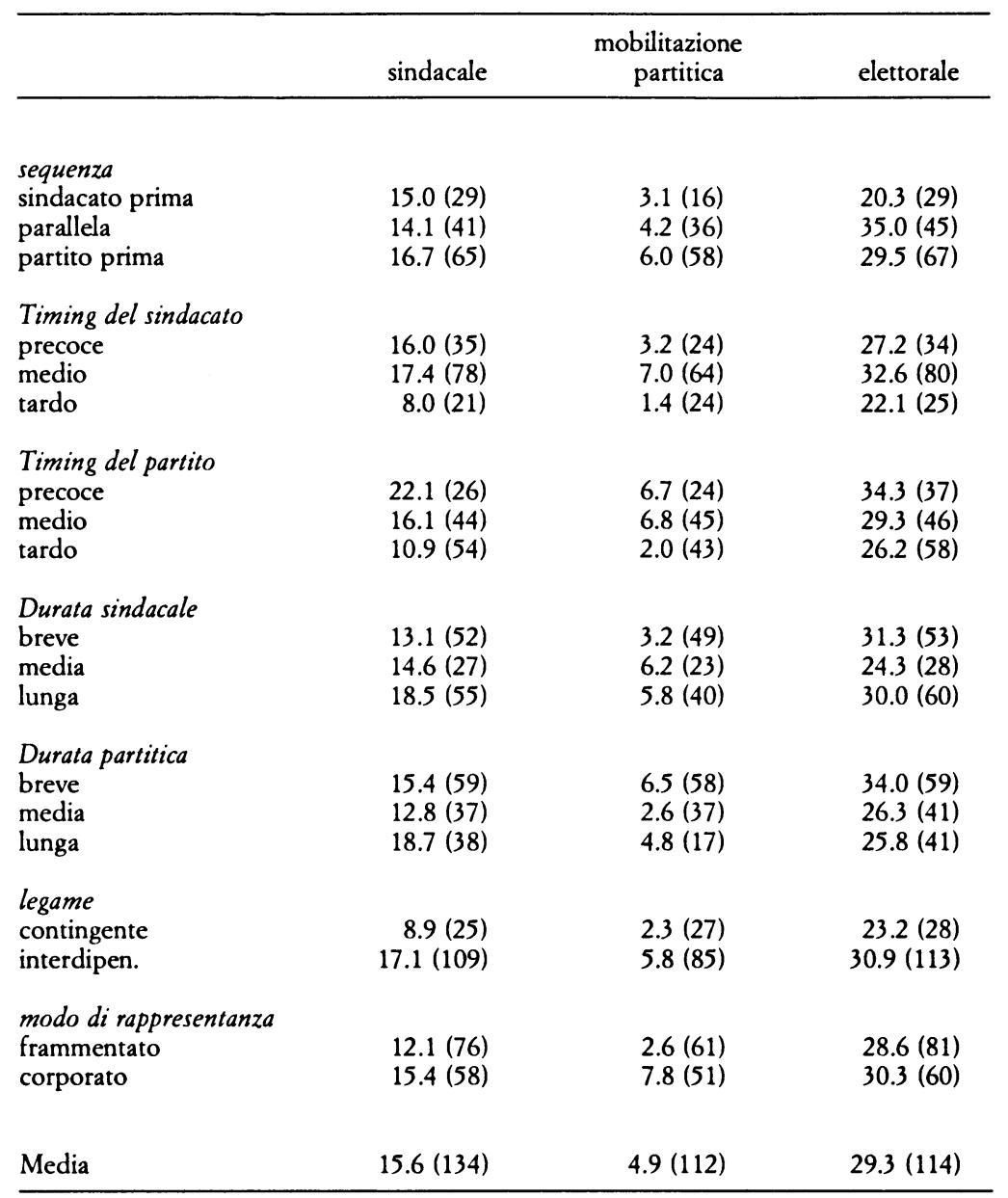

In parentesi il numero dei casi.

no avuto elezioni e il diritto di voto ha teso a convergere verso l'universalità (maschile) (massimo $\mathrm{N}=134$ elezioni).

La mobilitazione sindacale è favorita da un timing precoce del consolidamento organizzativo. Essa è due volte più alta in caso di precoce o medio consolidamento rispetto ai casi di consolidamento tardivo. Ed è influenzata anche dalla durata del processo di consolidamento, anche se in una direzione imprevi- 
sta: livelli più alti di mobilitazione corporata per i casi di processi di centralizzazione più lunghi piuttosto che per quelli più brevi. Va notato il forte impatto sulla mobilitazione sindacale di fattori connessi alla centralizzazione e alla rappresentanza politica: la mobilitazione sindacale è approssimativamente due volte più elevata 1) nei casi di precoce centralizzazione partitica; 2) nei casi di legame interdipendente partito-sindacato; e 3) (in misura minore) nei casi di modo di rappresentanza corporato rispetto a quello frammentato. Sorprende che fattori strettamente politici e rappresentativi abbiano una tale associazione con i livelli di mobilitazione sindacale. L'importanza del partito politico e dei suoi attivisti nel favorire lo sviluppo dei sindacati è sovente citata in riferimento alla «coscienza politica» del movimento sindacale, al suo coordinamento e centralizzazione e al suo riconoscimento dell'importanza dell'azione politica. Questi dati suggeriscono che fattori strettamente politici sono importanti anche per i puri e semplici livelli di mobilitazione degli iscritti.

Questo risultato deve essere letto alla luce dei fattori che influenzano la mobilitazione elettorale. In questo caso, il dato più significativo è che le variabili attinenti al processo di consolidamento organizzativo non hanno un forte impatto sui livelli di mobilitazione elettorale: le differenze nella mobilitazione elettorale media in rapporto alle variabili organizzative sono minime, e decisamente più basse che per le altre forme di mobilitazione. Ciò detto, tra i fattori che hanno un impatto troviamo solo fattori connessi al partito (sequenza in cui viene prima il partito; formazione precoce del partito; durata del processo di centralizzazione del partito) o al legame partito-sindacato. Un legame interdipendente partito-sindacato favorisce sia la mobilitazione sindacale sia quella elettorale. Viceversa, nessuno dei fattori connessi al consolidamento sindacale presenta una significativa associazione con la mobilitazione elettorale. A questo proposito si noti che mentre un modo frammentato di rappresentanza è associato a livelli sostanzialmente più bassi di mobilitazione sindacale, lo stesso non influenza assolutamente $i$ livelli di mobilitazione elettorale. Questi ultimi appaiono completamente indipendenti dalle modalità dello sviluppo organizzativo nel canale corporato. I fattori organizzativi e rappresentativi partitici influenzano la mobilitazione corporata assai più di quanto i fattori organizzativi corporati non facciano con la mobilitazione elettorale. 
La mobilitazione partitica è il canale più sistematicamente influenzato dagli aspetti del consolidamento organizzativo e quasi tutte le caratteristiche organizzative hanno un impatto significativo su di essa (quella più debole è la durata del processo di consolidamento del partito). Gli aspetti più importanti sono la sequenza (favorevole quella guidata dal partito), il timing del consolidamento di partito e, in particolare, il legame partito/ sindacato ed il modo di rappresentanza. Legami interdipendenti sono associati a livelli due volte e mezzo più alti di mobilitazione partitica; i casi di monopolio della rappresentanza sindacale e politica favoriscono una mobilitazione partitica tre volte più elevata di quella dei casi dove prevale la rappresentanza frammentata. I partiti che si sono sviluppati in stretta interpenetrazione organizzativa con movimenti sindacali unificati hanno tratto vantaggio dalla densa rete di connessioni organizzative incrociate.

Le dimensioni organizzative elencate nella tab. 4 possono essere ordinate da quelle presunte più favorevoli a quelle meno favorevoli sulla base di aspettative indipendenti dall'effettivo risultato che figura nella tabella. Così, per la mobilitazione sindacale si può avanzare l'ipotesi che le condizioni più favorevoli si verifichino quando il sindacato si organizza precocemente, prima del partito, in un breve lasso di tempo, con un legame interdipendente con il partito (o con una dipendenza del partito) e in presenza di un modo corporato di rappresentanza. Allo stesso modo, per la mobilitazione elettorale e partitica si può ipotizzare che la combinazione organizzativa più favorevole sia costituita da una sequenza guidata dal partito, un precoce e breve processo di centralizzazione partitica e, ancora una volta, un rapporto interdipendente con i sindacati ed una modalità corporata di rappresentanza. Le combinazioni opposte vanno consuiderate come le meno favorevoli. Seguendo questa logica, possiamo attribuire dei punteggi ad ogni variabile organizzativa per condurre un controllo statistico che ci confermi, per ogni specifica forma di mobilitazione, il fattore maggiormente discriminante (controllando l'effetto combinato di tutti) e il peso globale dell'intero insieme ${ }^{55}$. Il risultato è riportato nella tab. 5 .

\footnotetext{
35 Abbiamo ordinato le categorie attribuendo un punteggio da 1 a 3:

Sequenza sindacale: 3 = prima il sindacato; 2 = parallela; 1 = prima il partito;

Sequenza partitica: 3 = prima il partito; 2 = parallela; 1 = prima il sindacato;

Timing sindacale: 3 = precoce; 2 = medio; 1 = tardivo;
} 
Per ciascun tipo di mobilitazione, nella prima colonna si trova il risultato di una regressione realizzata con le sole variabili organizzative riguardanti quella specifica forma di mobilitazione (ovvero le variabili di consolidamento organizzativo del sindacato per la mobilitazione sindacale e le variabili partitiche per quella partitica ed elettorale). Nella seconda colonna tutte le variabili organizzative vengono utilizzate per ciascuna forma di mobilitazione.

Questo esercizio conferma e chiarisce quanto detto in riferimento alla tab. 4. Prima di tutto, comparando la varianza ed i coefficienti per le tre forme di mobilitazione si conferma che $i$ caratteri del consolidamento organizzativo hanno importanza assai maggiore per la mobilitazione partitica e sindacale che per la mobilitazione elettorale. In secondo luogo, comparando stavolta per ogni forma di mobilitazione i risultati della regressione con le variabili attinenti a quella forma con la regressione che include tutte le variabili, emerge un'importante differenza. Aggiungendo le variabili del consolidamento partitico alla regressione attinente alla mobilitazione sindacale, non solo l'associazione cresce, ma risulta altresì che tali variabili sono altrettanto o più importanti di quelle riguardanti il consolidamento organizzativo sindacale. Viceversa, quando aggiungiamo alla regressione attinente alla mobilitazione elettorale le variabili relative al consolidamento sindacale, non cambia niente in termini di associazione complessiva e molto poco nell'ordine o nel peso relativo dei fattori. Ciò conferma che la mobilitazione dell'elettorato socialista non è dipesa dalle forme di consolidamento organizzativo del canale corporato, mentre la mobilitazione sindacale è dipesa in misura apprezzabile dal modello di consolidamento partitico.

Si noti che la natura del modo di rappresentanza - corporato oppure frammentato - risulta un fattore di notevole rilievo nella determinazione dei livelli di adesione sindacale e ancor più partitica, ma di nessuna importanza per la mobilitazione elettorale. Le divisioni politiche ed organizzative incidono so-

Timing partitico: 3 = precoce; 2 = medio; 1 = tardivo;

Durata sindacale: $3=$ breve; $2=$ media; $1=$ lunga;

Durata partitica: 3 = breve; 2 = media; 1 = lunga;

Connessione: 3 = interdipendente; $1=$ contingente;

Modo di rappresentanza: 3 = corporato; 1 = frammentato.

Le regressioni sono condotte con il metodo stepwise, i criteri di inclusione sono fissati a 0,5 e 0,6 . 
TAB. 5. Peso relativo dei fattori organizzativi

\begin{tabular}{|c|c|c|c|c|c|c|c|}
\hline \multirow{8}{*}{$\begin{array}{l}\text { Var. } \\
\text { Modo Rapp. } \\
\text { Legame } \\
\text { Timing sind. } \\
\text { Durata sind. } \\
\text { Sequenza sind. }\end{array}$} & \multicolumn{6}{|c|}{ mobilitazione sindacale } & \multirow{4}{*}{ Par.cor. } \\
\hline & \multicolumn{3}{|c|}{ Variabili sindacali } & \multicolumn{3}{|c|}{ Tutte le variabili organizzative } & \\
\hline & r2 & Beta & Par. cor. & Var. & $\mathrm{r} 2$ & Beta & \\
\hline & .155 & .069 & .058 & Timing part. & .172 & .351 & \\
\hline & .174 & .283 & .250 & Modo Rapp. & .261 & .318 & .325 \\
\hline & .189 & .387 & 275 & Durata part. & .322 & -.284 & -.312 \\
\hline & .277 & -.539 & -.341 & Legame & .341 & .156 & .167 \\
\hline & .285 & .152 & .106 & & & & \\
\hline \multicolumn{8}{|c|}{ mobilitazione partitica } \\
\hline & \multicolumn{3}{|c|}{ Variabili partitiche } & \multicolumn{3}{|c|}{ Tutte le variabili organizzative } & \\
\hline Var. & r2 & Beta & Par. cor. & Var. & $\mathrm{r} 2$ & Beta & Par.cor. \\
\hline Modo Rapp. & .441 & .557 & .621 & Modo Rapp. & .441 & .862 & .594 \\
\hline Timing part. & .562 & .349 & .454 & Timing part. & .562 & .993 & .518 \\
\hline \multirow[t]{6}{*}{ Durata part. } & .567 & .072 & 103 & Durata part. & .567 & .087 & .092 \\
\hline & & & & Timing sind. & .570 & -1.037 & -.395 \\
\hline & & & & Durata sind. & .595 & .519 & .269 \\
\hline & & & & Sequenza Part. & .635 & -.622 & -.321 \\
\hline & & & & Legame & .637 & .066 & .080 \\
\hline & \multicolumn{6}{|c|}{ mobilitazione elettorale } & \\
\hline & \multicolumn{3}{|c|}{ Variabili partitiche } & \multicolumn{3}{|c|}{ Tutte le variabili organizzative } & \\
\hline Var. & r2 & Beta & Par. cor. & Var. & r2 & Beta & Par.cor. \\
\hline Durata part. & .100 & .259 & .259 & Durata part. & .100 & 196 & .192 \\
\hline Timing part. & .147 & .206 & .211 & Timing part. & .147 & .343 & .229 \\
\hline Legame & .167 & 193 & .185 & Legame & .167 & .147 & .151 \\
\hline \multirow[t]{4}{*}{ Modo Rapp. } & .178 & -.119 & -.113 & Modo rapp. & .178 & - & - \\
\hline & & & & Durata sind. & & .255 & .150 \\
\hline & & & & Timing sind. & .186 & -.203 & -.115 \\
\hline & & & & Modo rapp. & \multicolumn{2}{|c|}{ (var. rimossa) } & \\
\hline
\end{tabular}


prattutto sulla partecipazione degli iscritti al partito. Per natura, quest'ultima è una forma intermedia di partecipazione, che combina il carattere di adesione volontaria e attiva assai più «costosa» del voto (come la mobilitazione sindacale, in questo senso) al carattere di «lontananza» dagli specifici interessi ed attività funzionali (come la mobilitazione elettorale, in questo senso). «Costando» più del voto ed essendo più remota dagli interessi dell'adesione al sindacato, essa è logicamente più sensibile agli incentivi organizzativi e ideologici.

Sembra dunque che il legame tra le due forme di mobilitazione socialista, sindacale ed elettorale, sia nettamente meno diretto ed importante di quanto abitualmente si pensi. Torneremo su tale questione in sede di conclusione.

\section{La relazione tra forme diverse di mobilitazione}

Passiamo adesso alla relazione che esiste fra forme diverse di mobilitazione. In primo luogo vale la pena di considerare l'associazione tra di esse nel periodo 1900-1940 (tab. 6), dato che, a quanto ci risulta, nella letteratura che si è occupata della mobilitazione di classe tale semplice associazione non è stata mai esaminata su un'ampia scala comparativa. La correlazione più elevata si riscontra fra le due forme di mobilitazione volontaria degli aderenti (sindacale e partitica), e la più bassa quella fra mobilitazione elettorale e partitica. Nell'insieme delle 134 elezioni svoltesi fra il 1900 e il 1940 , la correlazione di .479 fra mobilitazione sindacale ed elettorale non appare particolarmente elevata. Soprattutto se si considera che essa si riferisce alla primissima fase della mobilitazione di classe, spesso associata, nei resoconti storici, all'«età dell'oro» degli allineamenti di classe e della chiara omogeneità sociale del sostegno socialista. In tempi successivi - così recita l'argomento - il modello è stato complicato dall'offuscamento dei confini di classe, dall'influenza dell' «imborghesimento», dalla contromobilitazione di movimenti religiosi o nazionalisti, e così via dicendo, in una lunga lista di spiegazioni del perché la classe sia ormai meno associata al comportamento politico di quanto non lo fosse in passato.

Una possibile spiegazione del modesto livello di associazione fra socialismo sindacale ed elettorale è che nei primi tempi della mobilitazione socialista i lavoratori già mobilitati nel canale corporato non avevano ancora trasferito tale adesione in pra- 
TAB. 6. Associazione tra $i$ diversi tipi di mobilitazione 1900-1940

\begin{tabular}{lccc}
\hline & elettorale & partitica & sindacale \\
\hline elettorale & - & $.237(114)$ & $.479(134)$ \\
partitica & - & - & $.532(112)$ \\
\hline
\end{tabular}

I casi sono anni elettorali.

tiche di voto per i partiti di classe a causa della mancanza di esperienza e/o di coscienza di classe, delle abitudini astensionistiche e delle posizioni apolitiche o antipolitiche anarco-sindacaliste. Soltanto con l'andar del tempo e con un lungo processo di educazione politica essi giungono a sviluppare l'abitudine alla politica elettorale e a comprenderne l'importanza. Se ciò fosse vero, ci si dovrebbe attendere un incremento nel tempo dell'associazione tra queste forme di impegno politico. Per essere più precisi, dovremmo aspettarci che la fase iniziale non sia caratterizzata da una forte associazione fra mobilitazione sindacale ed elettorale; che tale associazione cresca col tempo sino a raggiungere un livello massimo, e che in tempi più recenti declini nuovamente a causa del gran numero di fattori di distacco dagli allineamenti di classe precedentemente accennati. Per verificare questa ipotesi, la fig. 1 riporta i valori della correlazione fra mobilitazione sindacale ed elettorale per decennio, lungo un arco di tempo che copre quasi un secolo di politica elettorale. I valori delle correlazioni per decennio confermano tale ipotesi, con le più alte associazioni collocate negli anni trenta e quaranta, quelle intermedie negli anni dieci e venti e cinquanta-settanta, e con quasi nessuna associazione all'inizio e alla fine del secolo.

Nel contempo, questi dati suggeriscono un'altra conclusione. La correlazione di .479 fra il 1900 e il 1940 (tab. 6) (o di .491 nell'arco delle 314 elezioni svoltesi fra il 1880 e il 1990) va interpretata in una prospettiva di sviluppo temporale. Risponde alla domanda se la crescita nel tempo della sindacalizzazione si accompagna alla crescita nel tempo del sostegno elettorale. Dato che $i$ due processi seguono la stessa tendenza storica (verso la crescita), l'associazione può derivare in parte almeno da semplice multi-collinearità storica. Prendendo le correlazioni per decennio, il quesito in chiave di sviluppo temporale si trasforma in un quesito di tipo sincronico. All'interno di ciascun decennio 


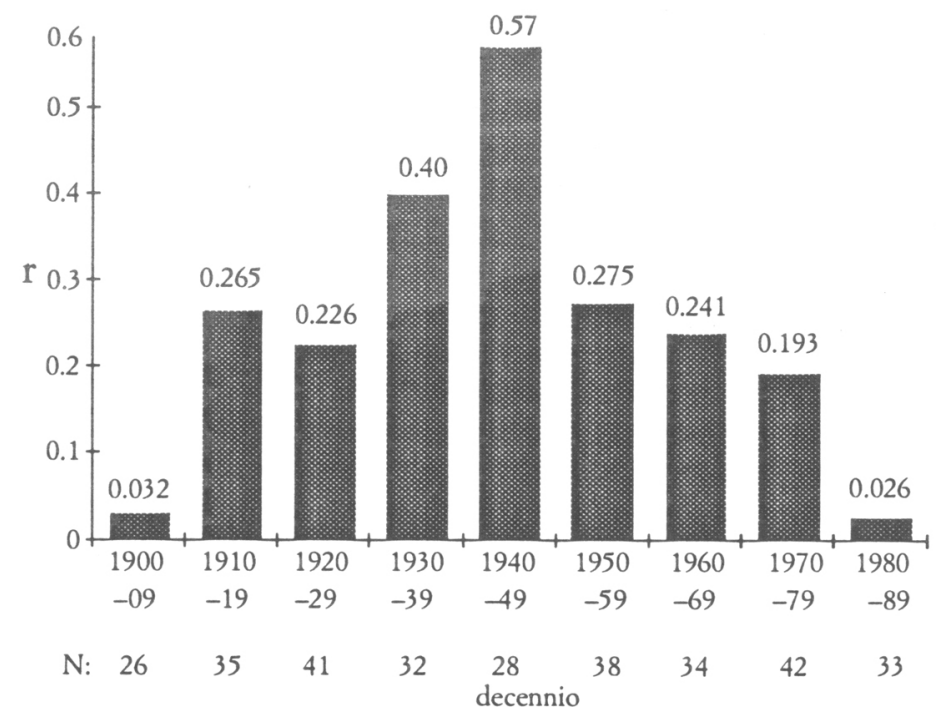

FIG. 1. Voti per la sinistra e densità sindacale: correlazione per decennio

l'influenza del tempo viene parametrizzata (ridotta al minimo), e la domanda è se, per ogni tempo $=\mathrm{ti}$, il socialismo elettorale sia stato più forte là dove il socialismo sindacale era più forte. La risposta è chiaramento «no» sino agli anni trenta (e dagli anni sessanta in poi). Fra il 1900 e il 1930 non è nei casi di più elevata mobilitazione sindacale che la sinistra elettorale è più forte.

Se confermati da ulteriori controlli, questi dati richiederanno qualche revisione storiografica. Se è mai esistita un'«età dell'oro» dell'allineamento di classe e dell'omogeneità sociale del sostegno socialista, essa non si situa certo nella fase iniziale, ma semmai nel periodo intermedio fra gli anni trenta e cinquanta. Ciò a sua volta sollecita una domanda per certi versi inusuale: chi votava per $i$ socialisti nei primi tempi? In termini di composizione di classe del voto socialista, la fase formativa dovrebbe essere considerata non meno problematica della più recente, diciamo dalla metà degli anni sessanta. Con un importante fattore di complicazione: l'assenza di dati di sondaggio.

Le misure di associazione generale non possono evidenziare le differenze fra un paese e l'altro. Un'osservazione dei dati più accurata dal punto di vista storico e nazionale si può ricavare $\mathrm{da}$ un'analisi della tab. 7. Qui i dati sono presentati in medie decennali per paese al fine di facilitare la comparazione tra pae- 
$\mathrm{T}_{\mathrm{AB}}$. 7. Livelli di mobilitazione sindacale, partitica e elettorale per decennio

\begin{tabular}{|c|c|c|c|c|c|c|c|c|}
\hline & & 1890 & 1900 & 1910 & 1920 & 1930 & $\begin{array}{c}\text { Media } \\
1880-1940\end{array}$ & $\begin{array}{r}\text { Media } \\
1900-1940\end{array}$ \\
\hline Austria & $\begin{array}{l}\text { sindacale } \\
\text { partitica } \\
\text { elettorale }\end{array}$ & & 21.0 & $\begin{array}{r}19.8 \\
7.7 \\
33.1\end{array}$ & $\begin{array}{l}39.7 \\
12.0 \\
40.0\end{array}$ & $\begin{array}{l}26.1 \\
16.9 \\
41.7\end{array}$ & $\begin{array}{l}28.5 \\
12.2 \\
34.0\end{array}$ & $\begin{array}{l}28.5 \\
12.2 \\
34.0\end{array}$ \\
\hline Belgio & $\begin{array}{l}\text { sindacale } \\
\text { partitica } \\
\text { elettorale }\end{array}$ & 8.8 & $\begin{array}{r}2.8 \\
22.5\end{array}$ & $\begin{array}{l}13.1 \\
\text { n.d. } \\
29.3\end{array}$ & $\begin{array}{l}23.6 \\
37.9\end{array}$ & 22.0 & 15.4 & $\begin{array}{r}15.3 \\
\text { (circa } 2.0) \\
31.9\end{array}$ \\
\hline Danimarca & $\begin{array}{l}\text { sindacale } \\
\text { partitica } \\
\text { elettorale }\end{array}$ & $\begin{array}{r}11.6 \\
5.2 \\
10.5\end{array}$ & $\begin{array}{r}10.4 \\
6.9 \\
23.9\end{array}$ & $\begin{array}{r}22.8 \\
8.7 \\
28.9\end{array}$ & $\begin{array}{r}27.6 \\
8.4 \\
34.9\end{array}$ & $\begin{array}{r}36.9 \\
9.9 \\
45.6\end{array}$ & $\begin{array}{r}21.9 \\
7.8 \\
24.7\end{array}$ & $\begin{array}{r}24.4 \\
8.4 \\
33.3\end{array}$ \\
\hline Finlandia & $\begin{array}{l}\text { sindacale } \\
\text { partitica } \\
\text { elettorale }\end{array}$ & & $\begin{array}{r}4.0 \\
5.5 \\
38.4\end{array}$ & $\begin{array}{r}9.1 \\
4.2 \\
42.2\end{array}$ & $\begin{array}{r}9.2 \\
2.1 \\
40.2\end{array}$ & $\begin{array}{r}4.7 \\
1.6 \\
37.7\end{array}$ & $\begin{array}{r}6.8 \\
3.4 \\
39.6\end{array}$ & $\begin{array}{r}6.8 \\
3.4 \\
39.6\end{array}$ \\
\hline Francia & $\begin{array}{l}\text { sindacale } \\
\text { partitica } \\
\text { elettorale }\end{array}$ & 9.9 & $\begin{array}{r}1.8 \\
0.3 \\
11.4\end{array}$ & $\begin{array}{r}4.5 \\
0.8 \\
18.6\end{array}$ & $\begin{array}{r}7.0 \\
1.3 \\
29.8\end{array}$ & $\begin{array}{r}13.7 \\
2.9 \\
36.2\end{array}$ & $\begin{array}{r}6.8 \\
1.3 \\
21.2\end{array}$ & $\begin{array}{r}6.8 \\
1.3 \\
24.0\end{array}$ \\
\hline Germania & $\begin{array}{l}\text { sindacale } \\
\text { partitica } \\
\text { elettorale }\end{array}$ & $\begin{array}{r}2.4 \\
23.4\end{array}$ & $\begin{array}{r}7.7 \\
4.0 \\
30.4\end{array}$ & $\begin{array}{r}20.4 \\
5.0 \\
40.2\end{array}$ & $\begin{array}{r}27.2 \\
3.0 \\
37.8\end{array}$ & $\begin{array}{r}21.1 \\
2.9 \\
35.4\end{array}$ & $\begin{array}{r}15.8 \\
3.7 \\
29.3\end{array}$ & $\begin{array}{r}19.1 \\
3.7 \\
36.0\end{array}$ \\
\hline Irlanda & $\begin{array}{l}\text { sindacale } \\
\text { partitica } \\
\text { elettorale }\end{array}$ & & & n.d. & $\begin{array}{r}22.0 \\
9.1\end{array}$ & $\begin{array}{r}19.5 \\
8.4\end{array}$ & 8.8 & $\begin{array}{r}20.8 \\
8.8\end{array}$ \\
\hline Italia & $\begin{array}{l}\text { sindacale } \\
\text { partitica } \\
\text { elettorale }\end{array}$ & $\begin{array}{l}1.1 \\
7.9\end{array}$ & $\begin{array}{r}2.6 \\
1.2 \\
17.8\end{array}$ & $\begin{array}{r}7.1 \\
0.6 \\
28.6\end{array}$ & $\begin{array}{r}9.9 \\
1.9 \\
29.9\end{array}$ & & $\begin{array}{r}6.5 \\
1.2 \\
21.1\end{array}$ & $\begin{array}{r}6.5 \\
1.2 \\
25.4\end{array}$ \\
\hline Paesi Bas. & $\begin{array}{l}\text { sindacale } \\
\text { partitica } \\
\text { elettorale }\end{array}$ & $\begin{array}{l}0.3 \\
1.4\end{array}$ & $\begin{array}{r}1.9 \\
0.9 \\
11.5\end{array}$ & $\begin{array}{r}9.6 \\
2.3 \\
21.8\end{array}$ & $\begin{array}{r}11.5 \\
1.2 \\
24.2\end{array}$ & $\begin{array}{r}14.0 \\
2.2 \\
25.7\end{array}$ & $\begin{array}{r}9.3 \\
1.4 \\
14.3\end{array}$ & $\begin{array}{r}9.3 \\
1.7 \\
20.8\end{array}$ \\
\hline Norvegia & $\begin{array}{l}\text { sindacale } \\
\text { partitica } \\
\text { elettorale }\end{array}$ & $\begin{array}{l}2.8 \\
0.5\end{array}$ & $\begin{array}{r}3.7 \\
3.6 \\
12.6\end{array}$ & $\begin{array}{r}13.0 \\
6.2 \\
30.0\end{array}$ & $\begin{array}{r}13.3 \\
4.5 \\
34.9\end{array}$ & $\begin{array}{r}24.7 \\
6.7 \\
39.3\end{array}$ & $\begin{array}{r}13.7 \\
4.8 \\
23.5\end{array}$ & $\begin{array}{r}13.7 \\
5.3 \\
29.2\end{array}$ \\
\hline Svezia & $\begin{array}{l}\text { sindacale } \\
\text { partitica } \\
\text { elettorale }\end{array}$ & $\begin{array}{l}3.1 \\
5.7\end{array}$ & $\begin{array}{r}11.3 \\
17.0 \\
9.2\end{array}$ & $\begin{array}{r}7.7 \\
7.7 \\
33.5\end{array}$ & $\begin{array}{r}19.1 \\
7.2 \\
42.4\end{array}$ & $\begin{array}{r}34.7 \\
9.3 \\
51.8\end{array}$ & $\begin{array}{r}15.1 \\
9.3 \\
34.2\end{array}$ & $\begin{array}{l}18.2 \\
10.3 \\
34.2\end{array}$ \\
\hline Svizzera & $\begin{array}{l}\text { sindacale } \\
\text { partitica } \\
\text { elettorale }\end{array}$ & $\begin{array}{l}1.1 \\
8.3\end{array}$ & $\begin{array}{r}3.5 \\
2.1 \\
15.1\end{array}$ & $\begin{array}{r}10.9 \\
3.9 \\
21.2\end{array}$ & $\begin{array}{r}12.9 \\
3.6 \\
27.4\end{array}$ & $\begin{array}{r}15.7 \\
4.6 \\
29.3\end{array}$ & $\begin{array}{r}8.8 \\
3.6 \\
20.3\end{array}$ & $\begin{array}{r}10.8 \\
3.6 \\
23.2\end{array}$ \\
\hline G. Bret. & $\begin{array}{l}\text { sindacale } \\
\text { partitica } \\
\text { elettorale }\end{array}$ & 8.7 & $\begin{array}{r}10.2 \\
3.1\end{array}$ & $\begin{array}{l}19.9 \\
11.6\end{array}$ & $\begin{array}{r}23.0 \\
0.8 \\
32.9\end{array}$ & $\begin{array}{r}18.6 \\
1.2 \\
36.4\end{array}$ & $\begin{array}{r}16.1 \\
1.0 \\
21.0\end{array}$ & $\begin{array}{r}17.9 \\
1.0 \\
21.0\end{array}$ \\
\hline media & $\begin{array}{l}\text { sindacale } \\
\text { partitica } \\
\text { elettorale }\end{array}$ & $\begin{array}{l}5.4 \\
3.0 \\
8.8\end{array}$ & $\begin{array}{r}5.4 \\
4.6 \\
18.1\end{array}$ & $\begin{array}{r}13.2 \\
4.7 \\
28.3\end{array}$ & $\begin{array}{r}18.9 \\
4.2 \\
32.4\end{array}$ & $\begin{array}{r}21.0 \\
5.8 \\
35.4\end{array}$ & & $\begin{array}{r}14.9 \\
4.8 \\
28.6\end{array}$ \\
\hline
\end{tabular}
n.d. = dato non disponibile. 
si, tra periodi e tra diverse forme di mobilitazione. A causa delle differenze nell'ampiezza del diritto di voto e nell'entità delle barriere anti-associative, il periodo più affidabile per una comparazione transnazionale è quello 1900-1940.

Il primo fatto da notare è che globalmente nell'esperienza del socialismo europeo la mobilitazione elettorale non è stata inferiore a quella sindacale. Casomai il contrario. Nel primo decennio del secolo, di fronte ad una media complessiva europea di mobilitazione elettorale attorno all' $8,8 \%$, la mobilitazione corporata era di circa il 5,4\%. Nel tempo, questo ritardo della mobilitazione sindacale si mantiene sino alla Seconda guerra mondiale. Solamente nella seconda metà del secolo la densità organizzativa dei sindacati di sinistra riesce a raggiungere o a superare la «densità» elettorale della sinistra. Fra il 1900 e gli anni trenta, la densità dei sindacati di sinistra si moltiplica per quattro, mentre la mobilitazione elettorale raddoppia solamente, ma alla fine di tale periodo la seconda è ancora più elevata della prima. Questa differenza sarebbe ancora più accentuata se invece di usare la densità sindacale - cioè il numero degli iscritti ai sindacati di sinistra in percentuale della forza-lavoro dipendente - si calcolasse la percentuale degli stessi rispetto all'elettorato. Questo offre un comune punto di riferimento migliore per la comparazione con le percentuali di voto. Tuttavia, essendo l'elettorato più ampio della forza-lavoro dipendente sin dagli anni novanta del XIX secolo, la percentuale dei membri dei sindacati di sinistra rispetto all'elettorato risulta notevolmente più bassa della stessa percentuale calcolata in proporzione al lavoro dipendente, rendendo il ritardo della mobilitazione dei sindacati di sinistra ancor più evidente. Si noti infine che la mobilitazione partitica è la più stabile di tutte. Fra il primo decennio del secolo e gli anni trenta non cambia granché, mentre sia la mobilitazione sindacale che quella elettorale crescono rapidamente.

Il quadro d'insieme cela le variazioni fra un paese e l'altro. La Finlandia è il caso più estremo di forte socialismo elettorale assolutamente non accompagnato dalla mobilitazione sindacale; i sindacati finlandesi non avvicinarono mai il precoce e considerevole successo del partito socialista (e poi comunista). La Germania segue un modello simile: soltanto dopo il 1910 si verifica un'improvvisa forte mobilitazione sindacale. Il movimento socialista danese, consolidatosi molto precocemente sul piano organizzativo, è l'unico caso di uno sviluppo perfettamente paral- 
lelo nei tre canali secondo una «crescita armonica». Esattamente il contrario di quanto accade nei casi britannico e irlandese; questi due sistemi - diversissimi in termini di industrializzazione, e perciò di dimensioni del lavoro dipendente - si assomigliano per la crescita sbilanciata: molto più forte nel canale sindacale che in quello elettorale, e sempre penosamente sottosviluppata in quello partitico. Francia e Italia si distinguono come casi simili di socialismo puramente «elettorale». La debolezza del movimento socialista tanto nel canale corporato quanto in quello partitico è stupefacente se la si compara con il suo sviluppo elettorale, non lontano dalla media. Si tratta di un movimento socialista la fonte della cui forza non risiedeva certamente nell'infrastruttura organizzativa. In conclusione, indipendentemente dal livello di associazione fra $i$ due fenomeni, la mobilitazione elettorale è stata generalmente più precoce ed elevata della mobilitazione sindacale.

Con l'andar del tempo, le esperienze dei vari paesi tendono a diventare più omogenee in termini elettorali; benché convergenti, rimangono più differenziate nella mobilitazione sindacale; mantengono profonde differenze nel canale della mobilitazione partitica. In questo ultimo settore, non c'è un solo esempio di inversione di tendenza o di recupero: i movimenti socialisti a debole mobilitazione partitica sono rimasti tali per l'intero periodo. In questa fase storica il socialismo austriaco offre un'impressionante immagine di capacità di mobilitazione partitica, con un iscritto al partito ogni 8 elettori. Il rapporto è di uno su 10 per la Danimarca e la Svezia e di uno a 16-18 per la Norvegia ${ }^{56}$. Nessun altro movimento socialista si avvicina a que-

56 Gran Bretagna, Svezia e Norvegia sono i tre paesi europei nei quali la membership socialista comprende sia iscritti individuali sia affiliazioni collettive tramite i sindacati. Per la Gran Bretagna, a partire dagli anni venti sono disponibili cifre separate per le adesioni individuali, e questi sono $i$ dati utilizzati nei nostri calcoli. Viceversa, per $i$ partiti laburisti svedese e norvegese non sono disponibili cifre separate per $\mathrm{i}$ titolari di tessere individuali. Alcune stime ipotizzano che in Svezia gli affiliati per via collettiva abbiano rappresentato circa il $70 \%$ del totale delle adesioni del dopoguerra. In Norvegia questa cifra è stimata intorno al $40 \%$ (Elvander 1977). Nei calcoli, le cifre relative alle iscrizioni a questi due partiti laburisti sono considerate assieme a quelle di partiti senza affiliazione collettiva, anche se ciò indebolisce la comparazione. In ogni caso, questo problema è meno decisivo di quanto non possa apparire in una prospettiva britannica. Infatti l'adesione indiretta, in particolare in Norvegia, non è canalizzata attraverso federazioni operanti a livello nazionale. Ogni unione locale prende una decisione sull'affiliazione con un voto a maggioranza. I membri individuali possono così «svincolarsi» abbastanza facilmente dalla decisione del gruppo. In termini finanziari, questo 
sti livelli di mobilitazione partitica all'interno dell'elettorato. Già casi intermedi come quelli della Germania e della Svizzera vedono un iscritto al partito ogni 30 elettori. Si comparino queste cifre con la situazione di strutturale e perdurante debolezza dei movimenti socialisti francese, italiano, olandese, belga, britannico e irlandese: un iscritto ai partiti ogni 60-100 elettori. Una situazione nella quale le attività partitiche di reclutamento, propaganda, lavoro sociale e via dicendo, devono essersi concentrate territorialmente in particolari regioni o aree urbane.

Prendendo come punto di riferimento le medie europee di mobilitazione nei tre canali, si possono distinguere quattro gruppi di casi. In Austria, Danimarca e Svezia la mobilitazione è alta in tutti e tre i canali; il movimento socialista ha un elevato sostegno elettorale che rispecchia il forte incapsulamento organizzativo dell'elettore socialista. La Norvegia è assimilabile a questi casi con livelli medi di mobilitazione in tutti e tre $i$ canali. All'altro estremo si collocano quei paesi nei quali la mobilitazione socialista è rimasta chiaramente al di sotto del livello medio complessivo europeo sia nell'ambito sindacale che in quelli partitico ed elettorale: prima di tutto i Paesi Bassi, poi la Svizzera, la Francia e l'Italia in ordine di mobilitazione elettorale crescente. Ciò che caratterizza comparativamente questi paesi è semplicemente la sotto-mobilitazione organizzativa del cleavage di classe in tutte le dimensioni. In Belgio e Finlandia, seppur con intensità diversa, il successo elettorale supera largamente quello sindacale e partitico. La Germania è un caso interessante che riproduce, a livelli più elevati di successo elettorale, il tipico modello britannico e irlandese: forte mobilitazione nel canale sindacale di fronte ad una mobilitazione più debole in quello partitico. Ciò è in contrasto con l'immagine corrente della socialdemocrazia tedesca come esempio storico di socialismo solido e fortemente organizzato ${ }^{57}$. Questa immagine rispondeva al vero nella primissima fase dello sviluppo del socialismo, fra il 1860 e il 1890, ma sbiadì rapidamente negli anni a cavallo fra $i$ due secoli. Essa derivava più dalla forte centralizzazione che da-

spesso non significa granché, dal momento che i sindacati sostengono il partito attingendo ad un fondo comune senza specificare i nomi dei sottoscrittori (cfr. Rokkan e Valen 1962), ma in termini sostanziali questo tipo di affiliazione indica un coinvolgimento politico più consapevole nel partito di quello riscontrabile nel caso britannico.

57 Cfr. Breitmen $(1981,6)$ : «... con un numero di iscritti che superava il milione nel 1914, la SPD era il più vasto e meglio organizzato partito socialista d'Europa». 


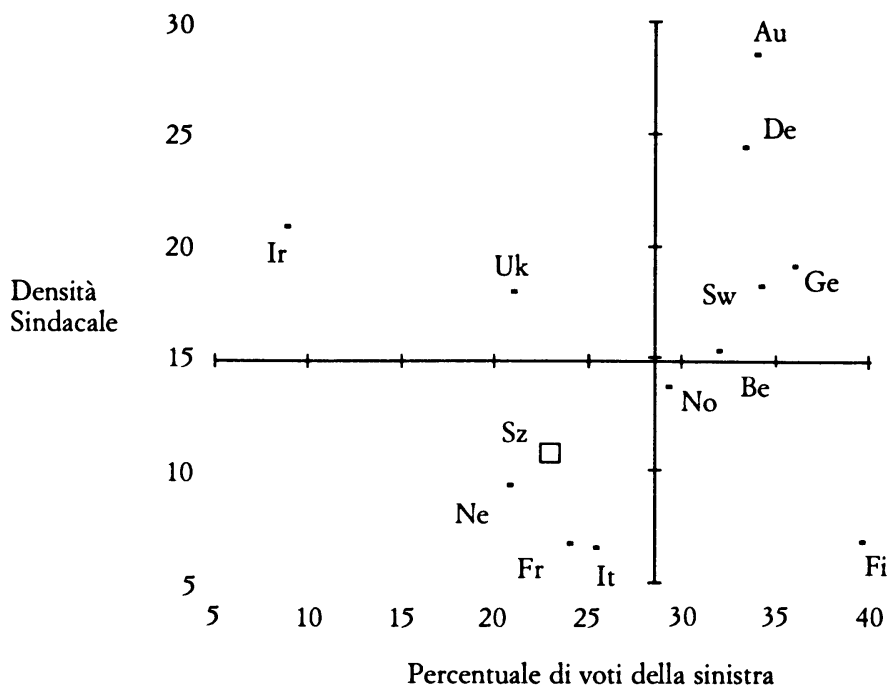

FIG. 2. Mobilitazione sindacale e elettorale (1900-1940)

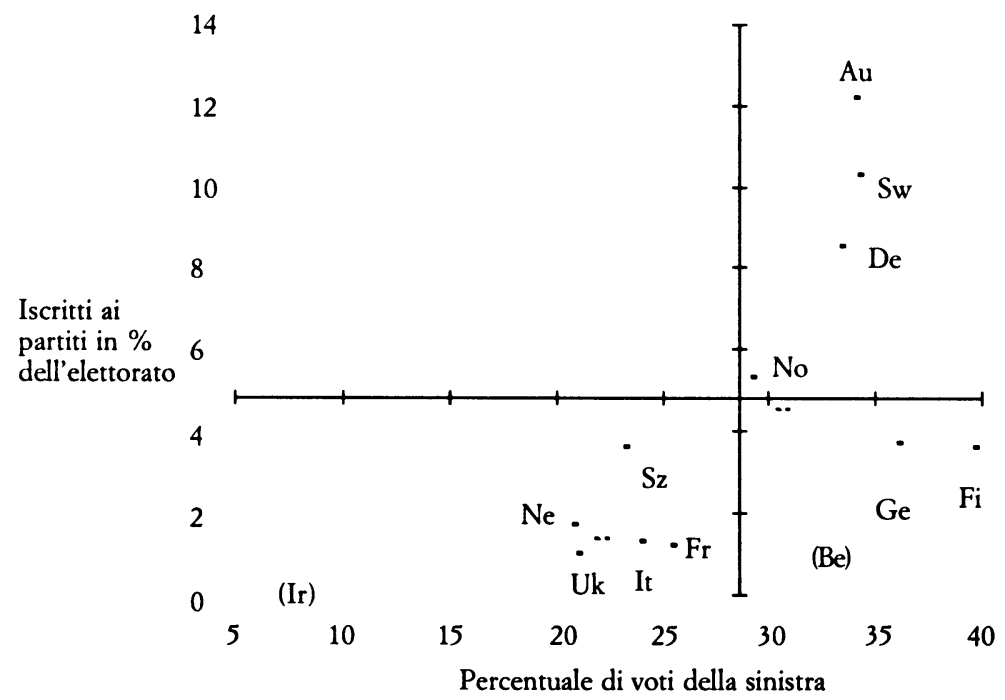

FIG. 3. Mobilitazione elettorale e partitica (1900-1940) 
gli effettivi livelli di mobilitazione partitica. Gran Bretagna e Irlanda, infine, rappresentano casi evidenti di mobilitazione elettorale ritardata e mobilitazione partitica estremamente debole nel contesto di una alta e precoce mobilitazione sindacale. Le figg. 2 e 3 sintetizzano la discussione sin qui condotta, riproducendo graficamente $\mathrm{i}$ livelli medi di mobilitazione sindacale e partitica per ciascun paese nel periodo $1900-1940$ e ponendoli a confronto con i corrispondenti livelli di mobilitazione elettorale.

\section{Chi si è mobilitato per primo?}

Il problema della misura in cui gli elettori socialisti erano già stati precedentemente mobilitati in altri canali può essere considerato in modo più diretto osservando la presenza di iscritti a partiti e sindacati di sinistra in percentuale rispetto ai voti raccolti dagli stessi partiti di sinistra. Le tabb. 8 e 9 riportano questi dati per paese e per decennio. Queste cifre indicano il numero di iscritti ai sindacati e ai partiti di sinistra ogni 100 votanti per tali partiti. Le cifre superiori a 100 indicano situazioni in cui gli aderenti a sindacati e partiti di sinistra superavano in numero gli elettori della sinistra. Porre la mobilitazione sindacale e partitica in relazione con $\mathrm{i}$ voti ottenuti dai partiti di sinistra rende tale fenomeno fortemente dipendente dalle variazioni temporali dei risultati elettorali. Perciò, queste cifre non sono ideali per comparazioni diacroniche, dal momento che dipendono da variazioni concomitanti di entrambe le dimensioni, ma sono indicative per una comparazione sincronica tra paesi diversi.

In tre paesi la mobilitazione sindacale precede cronologicamente quella elettorale: Danimarca, Svezia e Regno Unito. La Svizzera mantiene una proporzione relativamente alta fra membri dei sindacati ed elettori socialisti: quasi uno su uno. In tutti gli altri casi, il socialismo elettorale già a cavallo fra i due secoli era sostenuto da un ampio settore di elettori non precedentemente mobilitati in altro modo. C'era un iscritto ai sindacati di sinistra più o meno ogni due elettori di sinistra in Italia, Austria, Belgio, Germania; uno ogni due e mezzo in Norvegia e nei Paesi Bassi; un elettore sindacalizzato ogni $3-4$ voti di sinistra in Francia.

Le differenze sono più pronunciate nel rapporto tra elettori 
TAB. 8. Iscritti ai sindacati di sinistra in percentuale degli elettori di sinistra (medie decennali)

\begin{tabular}{lrrrrr}
\hline & 1900 & 1910 & 1920 & 1930 & $\begin{array}{c}\text { Media } \\
1900-40\end{array}$ \\
\hline Austria & & 42 & 65 & 40 & 49 \\
Belgio & 11 & 50 & 72 & 63 & 49 \\
Danimarca & 132 & 105 & 53 & 53 & 86 \\
Finlandia & 7 & 13 & 17 & 8 & 11 \\
Francia & 23 & 34 & 33 & 52 & 36 \\
Germania & 43 & 50 & 50 & 35 & 44 \\
Irlanda & & & 125 & 126 & 126 \\
Italia & 88 & 44 & 52 & & 61 \\
Paesi Bassi & 30 & 69 & 32 & 34 & 41 \\
Norvegia & 52 & 47 & 29 & 36 & 41 \\
Svezia & 671 & 57 & 60 & 50 & 209 \\
Svizzera & 67 & 126 & 77 & 96 & 93 \\
Gran Bretagna & 1238 & 306 & 80 & 48 & 418 \\
& & & & & \\
Media & 214 & 78 & 57 & 53 & 98 \\
\hline
\end{tabular}

$\mathrm{T}_{\mathrm{AB}}$. 9. Iscritti ai partiti di sinistra in percentuale degli elettori di sinistra (medie decennali)

\begin{tabular}{|c|c|c|c|c|c|}
\hline & 1900 & 1910 & 1920 & 1930 & $\begin{array}{c}\text { Media } \\
1900-40\end{array}$ \\
\hline Austria & & 39 & 48 & 46 & 44 \\
\hline Belgio & & n.d. & & & (13) \\
\hline Danimarca & 51 & 40 & 47 & 44 & 46 \\
\hline Finlandia & 22 & 17 & 14 & 21 & 19 \\
\hline Francia & 5 & 7 & 11 & 20 & 11 \\
\hline $\begin{array}{l}\text { Germania } \\
\text { Irlanda }\end{array}$ & 16 & $\begin{array}{r}15 \\
\text { n.d. }\end{array}$ & 20 & 16 & $\begin{array}{l}17 \\
(6)\end{array}$ \\
\hline Italia & 11 & 4 & 13 & & 10 \\
\hline Paesi Bassi & 10 & 14 & 10 & 15 & 12 \\
\hline Norvegia & 75 & 36 & 46 & 40 & 49 \\
\hline Svezia & 342 & 34 & 51 & 47 & 119 \\
\hline Svizzera & 27 & 42 & 19 & 71 & 39 \\
\hline Gran Bretagna & & & 12 & 20 & 16 \\
\hline Media & 62 & 25 & 26 & 34 & 36 \\
\hline
\end{tabular}

Le cifre in parentesi sono stime.

e iscritti ai partiti. In Svezia, Norvegia e Danimarca si può dire che la mobilitazione partitica abbia preceduto quella elettorale (sfortunatamente non sono disponibili cifre anteriori al 1913 per quanto riguarda gli iscritti al partito socialista austriaco). $\mathrm{Nel}$ primo decennio del secolo si contavano 3,5 iscritti al parti- 
to per ogni voto in Svezia; due terzi di iscritto per ogni voto in Norvegia e un iscritto ogni due voti in Danimarca. Queste differenze originarie hanno teso a ridursi col tempo, ma non sono mai state cancellate. Nel periodo 1900-1940, Norvegia, Danimarca, Austria e Svezia avevano un iscritto socialista ogni due voti. Invece Italia, Francia, Germania, Paesi Bassi e Regno Unito (sulla base di stime del periodo si potrebbero aggiungere Belgio e Irlanda) avevano solo un iscritto ogni 6-10 voti.

Questi dati possono essere letti in due diverse prospettive. Li si può considerare come indicativi del «costo» di un voto rispetto a quello di un iscritto al sindacato o al partito. In quei casi in cui la proporzione fra iscritti e elettori è bassa, si può supporre che la mobilitazione elettorale non richiedesse una forte infrastruttura organizzativa; che il socialismo elettorale avesse altre e diverse fonti di attrazione elettorale; in breve, che $i$ voti fossero a basso costo organizzativo. In alternativa, si possono leggere i dati in termini di solidità del radicamento elettorale del socialismo sulla base dell'incapsulamento organizzativo del suo elettorato. Sta di fatto che nel lungo periodo i socialismi solidamente incapsulati si sono dimostrati più stabili elettoralmente e più «egemonici» socialmente di quelli debolmente incapsulati, ma non necessariamente più forti in termini puramente elettorali.

\section{Alcuni rilievi conclusivi}

Il saggio ha documentato l'estesa variabilità a livello nazionale tanto dei modelli di iniziale consolidamento centrale quanto di successiva mobilitazione sindacale, partitica ed elettorale. Da prospettive diverse si è ripetutamente sottolineata la diversità della «logica» che determina lo sviluppo del socialismo sindacale rispetto a quella che governa il socialismo politico, la mancanza di una forte associazione fra i due fenomeni, la preminenza del secondo sul primo. I risultati indicano tipi qualitativamente diversi di movimenti socialisti in fase di primo sviluppo, caratterizzati da un diverso mix di mobilitazione organizzativa. Azzardiamo la seguente distinzione in quattro tipi basilari: 


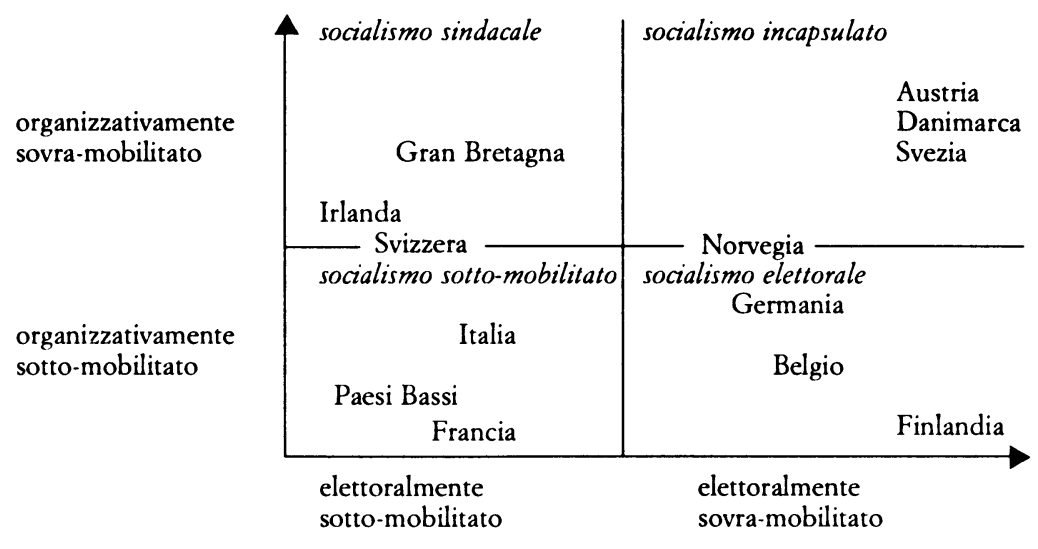

Il socialismo sindacale era più mobilitato nel canale corporato che in quello elettorale. Il socialismo incapsulato era densamente organizzato e strettamente interrelato in tutti i canali. Il socialismo elettorale (o ideologico) era assai più forte sul terreno elettorale che su quello organizzativo. Infine, il socialismo sottomobilitato era semplicemente in ritardo omogeneo in tutte le sfere di mobilitazione. Caratterizzazioni tipologiche così ampie offrono normalmente più domande che risposte; sono però utili per mettere in evidenza le domande che hanno bisogno di una risposta. $\mathrm{Ci}$ sia pertanto consentito di azzardare un certo numero di conclusioni più ampie e di ipotesi per ulteriori ricerche.

In primo luogo, questa ricerca ha sottolineato la necessità di separare tra di loro le interpretazioni della mobilitazione sindacale, partitica ed elettorale. La forma in cui si è svolto il consolidamento iniziale di organizzazioni specifiche, tanto nel canale di rappresentanza degli interessi quanto in quello del voto e dell'azione politica diretta, è stata importante per le successive ondate di mobilitazione politica di massa. L'impatto di quel modello iniziale ha esercitato più influenza sulla mobilitazione sindacale e partitica che su quella elettorale. Nella maggior parte dei casi, sin dall'inizio il socialismo elettorale si è esteso molto al di là dei settori politicamente mobilitati del movimento sindacale. Le poche eccezioni a questo quadro generale sono importanti; è proprio là dove l'iniziale mobilitazione sindacale $\mathrm{e}$ partitica hanno preceduto o affiancato quella elettorale che nel lungo periodo il socialismo si è dimostrato più capace di cogliere successi, più stabile sul piano elettorale; in una parola, più 
«egemonico». Questa constatazione non toglie che alcuni movimenti socialisti hanno ottenuto un largo seguito elettorale senza fare affidamento su altre forme di mobilitazione pre-elettorale e sono riusciti a mantenere ed accrescere la loro forza basandosi su legami e basi organizzative esili. Il socialismo elettorale è stato sin dall'inizio sostenuto da alleati elettorali - più o meno voluti - che sicuramente erano legati al socialismo da una motivazione politico-ideologica, ma non erano incapsulati nella sua rete organizzativa ${ }^{58}$. L'interpretazione del socialismo sindacale e partitico e di quello elettorale non deve necessariamente partire dagli stessi presupposti e una chiara distinzione tra questi due canali può aiutare a riconciliare le spiegazioni spesso divergenti dello sviluppo socialista sub specie di «risposta economica» e di «risposta politica». Queste due dimensioni sono spesso considerate come due facce del medesimo processo, ma l'ancora incompleta analisi condotta in questo saggio suggerisce che esse richiedono modelli esplicativi diversi.

Un secondo punto importante legato a quanto sopra detto è che se consideriamo i casi di sovra-mobilitazione elettorale - e più in generale di mobilitazione elettorale più ampia di quella sindacale e partitica - essi paiono verificarsi in particolare 1) dove una lunga esperienza di governo autoritario ha costretto il movimento socialista a considerare prioritari obiettivi politici di democratizzazione e liberalizzazione; e, in misura più limitata, 2) dove la mobilitazione politica religiosa ha orientato verso il socialismo settori dell'elettorato motivati da atteggiamenti razionalistici e anticlericali. In entrambi questi casi, il socialismo elettorale ha potuto attrarre più facilmente settori delle classi

58 Questo rilievo, come altri espressi a più riprese nel saggio, solleva qualche dubbio sulla tesi che il primo socialismo abbia mobilitato prevalentemente gli operai perché si rivolgeva ad essi come ad una «classe» $\mathrm{e}$ in seguito abbia iniziato a perdere quote del loro sostegno per la decisione di rivolgersi alla classe media e di fare appello agli individui in quanto «cittadini» invece che «operai». Per questa tesi si vedano Przeworski (1985) e Przeworski e Sprague (1986). Senza mettere in discussione gli assunti «razionalistici» di questa linea di ragionamento - e il tipo alquanto unidimensionale di operaio che essa postula - un approccio al socialismo elettorale incentrato sulla scelta strategica delle élites e sulla risposta razionale data ad esse dagli operai è storicamente poco convincente. Come la disparità delle varie forme di mobilitazione suggerisce, le «alleanze» e l'eterogeneità sociale erano una caratteristica del primo socialismo elettorale. È persino probabile che in molti casi esso sia stato notevolmente sostenuto dalle (vecchie) classi medie e col tempo lo sia stato meno. Circostanze esterne alle specifiche scelte strategiche del socialismo organizzato sembrano aver svolto un ruolo importante nello sviluppo del suo sostegno elettorale. 
medie, mentre è stato nel contempo obbligato ad abbandonare il monopolio rappresentativo del sindacalismo organizzato. $\grave{E}$ importante sottolineare che questi aspetti sono stati tradizionalmente considerati alla stregua di inconvenienti per il socialismo, poiché ne danneggiavano la possibilità di piena mobilitazione della classe operaia; ma essi costituivano un inconveniente per il socialismo sindacale, non necessariamente per quello elettorale. Ciò che queste circostanze gli hanno sottratto in termini di sostegno sindacale organizzato, può esser stato restituito in termini di sostegno ideologico delle classi medie. Ovviamente, questo fatto ha prodotto tipi diversi di movimenti socialisti: diversi appunto nella natura del rapporto fra sostegno elettorale, partitico e sindacale.

Ciò conferma la necessità di distinguere chiaramente la risposta all'ambiente burocratico-statale da quella all'ambiente economico di classe nella storia del socialismo ${ }^{59}$. Le condizioni dello sviluppo economico e industriale - la «maturità delle condizioni socio-economiche» - sono più determinanti per i livelli della mobilitazione sindacale che per quelli della mobilitazione politica. In quest'ultimo caso la relazione appare in un certo senso inversa. Il socialismo elettorale può profittare dell'opposizione burocratico/statale cui deve far fronte, e svilupparsi prima e più facilmente là dove in tale sfera è costretto a combattere per obiettivi non raggiunti da movimenti politici liberal-democratici deboli o inefficaci (abolizione dei residui feudali, allargamento del suffragio, parlamentarizzazione, separazione chiesa-stato, limitazione dei poteri burocratici, anti-militarismo, ecc.). Viceversa, il precoce e meno controverso raggiungimento di questi obiettivi, pur rendendo la mobilitazione nel canale degli interessi più semplice e rapida, ha causato nel contempo un ritardo della mobilitazione partitica ed elettorale. In questo caso, né il movimento sindacale ha avuto bisogno di sviluppare rapidamente uno specifico strumento politico - poteva prestare il suo crescente sostegno organizzativo ad altri candidati o organizzazioni politiche simpatizzanti - né il socialismo elettorale ha potuto rivolgere il suo appello attraverso temi e problematiche in grado di ottenere consensi al di fuori dei gruppi già mobilitati sul piano sindacale.

Un'altra constatazione importante emerge leggendo lo sche-

59 Su questo tema si vedano le riflessioni di Szabo (1982). 
ma lungo la direttrice della sotto-mobilitazione organizzativa. La frammentazione politica del movimento socialista ha chiaramente danneggiato la mobilitazione sindacale, ma non quella elettorale. Più specificamente, in tutti quei casi in cui la scissione comunista è stata coronata da successo in termini organizzativi - in particolare Francia, Germania, Finlandia e Italia ${ }^{60}$ - il movimento socialista poggiava su un incapsulamento organizzativo relativamente esile sia nella dimensione partitica che in quella sindacale, entrambe largamente inferiori alla sua mobilitazione elettorale. Questo dato suffraga la tesi secondo cui le prospettive di successo della frattura comunista vennero accresciute dalla debolezza dell'incapsulamento organizzativo della classe operaia nel movimento socialista subito dopo la Prima guerra mondiale. In questi casi, l'elettorato socialista era composto da settori relativamente ampi non collegati organizzativamente con il partito e $i$ sindacati socialisti, e la ritardata sindacalizzazione e mobilitazione partitica di massa si verificò proprio durante il periodo di massimo richiamo della rivoluzione russa. La competizione organizzativa tra socialisti e comunisti non si svolse all'interno di vasti ed istituzionalizzati movimenti corporati, bensì in organizzazioni deboli, soggette al rapido e crescente reclutamento di settori della classe operaia in precedenza non mobilitati (e perlopiù non specializzati).

Rimangono aperte un certo numero di questioni più specifiche: quali radici extra-organizzative ha l'eccezionale successo elettorale del socialismo finlandese nei primi vent'anni del secolo? E al contrario, che spiegazione si può dare dell'eccezionale sotto-mobilitazione elettorale del socialismo irlandese? Perché i movimenti olandese, italiano e francese furono così sotto-mobilitati sul piano organizzativo? Esistevano delle reti extra- o prepolitiche che resero più facile al socialismo scandinavo e au-

60 Il movimento socialista norvegese viene spesso descritto come profondamente scosso dalla frattura socialismo/comunismo. Questa caratterizzazione nasce dalla estrema radicalizzazione di tale movimento dopo la Prima guerra mondiale e dell'analisi fattane da Bull (1922). Ripresa da Galenson, tale caratterizzazione si è consolidata. Tuttavia, anche se la radicalizzazione del movimento operaio norvegese è stata particolarmente acuta (quantomeno per lo standard scandinavo), non la si deve confondere con la natura più o meno profonda della scissione tra comunisti e socialisti. Il partito socialista aderì in modo largamente maggioritario e ordinatamente alla Terza Internazionale così come in modo altrettanto maggioritario e ordinato ritornò nella Seconda tre anni dopo. La frammentazione sia organizzativa che ideologica fu minima, assolutamente non paragonabile a quella degli altri casi elencati nel testo. 
striaco la creazione di un «lagen» organizzativo di densità impressionante? La letteratura sui singoli casi nazionali non è avara di risposte specifiche. Non è facile però renderle compatibili con uno schema comparativo senza produrre una lista di spiegazioni ad hoc.

Infine, un richiamo a quanto questo lavoro ha esplicitamente escluso dal suo ambito ed al contesto più ampio in cui dovrebbe calarsi. In questo articolo ci siamo concentrati sullo sviluppo organizzativo perché riteniamo che questo sia il settore meno sviluppato della storia comparata del socialismo. Tuttavia, per ulteriori ricerche e un più accurato controllo, i dati organizzativi devono essere integrati con i dati riguardanti altre tre dimensioni omesse in questa sede. La prima dimensione riguarda la base di sostegno, cioè la dimensione, il tipo e la composizione della classe operaia: il più classico punto di partenza dell'analisi della mobilitazione socialista. La seconda dimensione riguarda la sequenza temporale dello sviluppo dei diritti fondamentali di partecipazione e di incorporazione elettorale e associativa; si deve guardare alla sequenza temporale, alla facilità e alle modalità di entrata del movimento socialista nel sistema politico. Infine, la terza dimensione dimenticata è quella ideologica. La mobilitazione politica non è solamente sviluppo di capacità strumentali, e sfruttamento di opportunità politiche, ma anche formazione di identità e gestione di emozioni. In questa sede non si è fatto riferimento all'originario orientamento ideologico dei primi agitatori e ideologi socialisti, alla penetrazione delle loro idee nel movimento socialista e in generale al grado e alla natura dello scontro ideologico interno. Questi aspetti hanno avuto un grande peso sulle decisioni di impegnarsi o meno nella specifica azione politica; sulla scelta dell'arena in cui gettare le risorse mobilitate; sulla negoziabilità delle istanze dei primi movimenti socialisti e sulle risposte che gli avversari e l'ambiente esterno gli hanno proposto. La verifica di macro-ipotesi sullo sviluppo storico della sinistra di classe europea richiede uno schema che sappia collegare mobilitazione organizzativa, condizioni socio-strutturali, caratterizzazioni ideologiche e struttura delle opportunità politiche. 
Riferimenti bibliografici

Alford, R. e R. Friedland (1974), Nations, Parties and Participation: A Critique of Political Sociology, in «Theory and Society», 1, pp. 307-328.

Bain, G.S. e R. Price (1976), Profiles of Union Growth. A Comparative Statistical Portrait of Eight Countries, Oxford, Blackwell.

Balthasar, A., E. Gruner e H. Hirter (1988), Gewerkschaften und Arbeitgeber auf dem Arbeitsmarkt: Streks, Kampf ums Recht und Verbältnis zu anderen Interessengruppen, vol. 1 di Arbeiterschaft und Wirtschaft in der Schweiz 1880-1914, Bern, Chronos.

Bartolini, S. (1983), The Membership of Mass Parties: The Social Democratic Experience, 1889-1978, in H. Daalder e P. Mair (a cura di), Western European Party Systems. Continuity and Change, London, Sage.

Bartolini, S. e P. Mair (1990), Identity, Competition and Electoral Availability. The Stabilization of the European Electorates 18851985, Cambridge, Cambridge University Press.

Berglund, S. e U. Lindström (1978), The Scandinavian Party System(s), Lund, Studentlitteratur.

Berresford Ellis, P. (1972), A History of Irish Working Class, London, Victor Gollancz.

Breitmen, R. (1981), German Socialism and Weimar Democracy, Chapel Hill, University of North Carolina Press.

Bull, E. (1922), Die Entwicklung der Arbeiterbewegung in den drei skandinavischen Ländern, in «Archiv für die Geschichte des Sozialismus und der Arbeiterbewegung», X, pp. 329-361.

Cartiglia, C. (1976), Rinaldo Rigola e il sindacalismo riformista in Italia, Milano, Feltrinelli.

Chubb, B. (1974), The Government and Politics of Ireland, London, Oxford University Press.

Coulter, P. (1975), Social Mobilization and Liberal Democracy. A Macro-quantitative Analysis of Global and Regional Models, Farnborough Hants, Lexington Books.

Daalder, H. (1966a), Parties, Elites, and Political Development in Western Europe, in J. La Palombara e M. Weiner (a cura di), Political Parties and Political Development, Princeton, Princeton University Press, pp. 43-77.

- (1966b), The Netherlands: Opposition in a Segmented Society, in R.A. Dahl (a cura di), Political Opposition in Western Democracies, New Haven, Yale University Press, pp. 188-236.

Delsinne, L. (1936), Le mouvement syndical en Belgique, Bruxelles, Castaigne.

Deutsch, K. (1961), Social Mobilization and Political Development, in «American Political Science Review», LV, pp. 493-502, trad. it. 
parziale in G. Sartori (a cura di), Antologia di scienza politica, Bologna, Il Mulino, 1970, pp. 461-474.

Duverger, M. (1956), Les partis politiques, Paris, Colin, trad. it. I partiti politici, Milano, Comunità, 1961.

Ebbinghaus, B. (1992), The Transformation of Cleavage Structures in Western European Trade Union Systems. Can we draw Union Diversity in Rokkan's Conceptual Map?, relazione presentata alle Joint Sessions ECPR, Limerick, aprile 1992.

Elvander, N. (1977), Scandinavian Social democracy: Present Trends and Future Prospects, relazione presentata al Workshop ECPR, Berlin, marzo 1977.

Flora, P. (1973), Historical Processes of Social Mobilization: Urbanization and Literacy 1850-1965, in E.E. Eisenstadt e S. Rokkan (a cura di), Building States and Nations, vol. 1, Models and Data Resources, London, Sage, pp. 213-258.

Foverskov, P. e L.N. Johansen (1978), The Socialist and Communist Parties in Denmark in a Century: History, Programs and Policy, non pubblicato.

Galenson, W. (1949), Labour in Norway, New York, Russel \& Russel.

- (1952a), The Danish System of Labor Relations, New York, Russel \& Russel.

- (1952b), Comparative Labour Movements, New York, Prentice Hall.

Gallagher, M. (1982), The Irish Labour Party in Transition 1957-1982, Manchester, Manchester University Press.

Garbani, P. e J. Schmid (1980), Le syndicalisme suisse. Histoire politique de l'Union Syndicale 1880-1980, Lausanne, Editions d'en bas.

Gass, S. (1988), Les débuts du Parti Socialiste Suisse, 1870-1890, in Cent Ans de PSS 1888-1988, Lausanne, Editions d'en bas.

Harbridge House Europe (1967), Business Representation in Irish $\mathrm{Na}$ tional Affairs, Dublin.

Horowitz, D.L. (1976), Storia del movimento sindacale in Italia, Bologna, Il Mulino.

Katz, R. e P. Mair (1992), The Membership of Political Parties in European Democracies, 1960-1990, in «European Journal of Political Research», XXII, pp. 329-345.

Klenner, F. (1951), Die Oesterreichischen Gewerkschaften, vol. 1, Wien.

Knopp, K. (1980), Austrian Social Democracy 1889-1914, Washington (DC).

Kossman, E.H. (1978), The Low Countries 1780-1940, Oxford, Clarendon Press.

Kuhnle, S. (1975), Patterns of Social and Political Mobilization. A Historical Analysis of the Nordic Countries, London, Sage.

MacCarthy, C. (1977), Trade Unions in Ireland 1894-1960, Dublin, Institute of Public Administration. 
Malefakis, E.E. (1973), A Comparative Analysis of Workers Movements in Spain and Italy, relazione presentata al convegno dell'American Historical Association, San Francisco, dicembre 1973.

Mitchell, A. (1974), Labour in Irish Politics, 1890-1930, Dublin, Irish University Press.

Nedelmann, B. (1975), Handlungsraum politischer Organisationen, in «Sozialwissenschaftliches Jahrbuch für Politik», 4, pp. 9-118.

- (1987), Individuals and Parties. Changes in the Processes of Political Mobilization, in «European Sociological Review», 3, pp. 181202.

Nettl, P.J. (1967), Political Mobilization, New York, Basic Books.

Neumann, S. (1956), Toward a Comparative Study of Political Parties, in S. Neumann (a cura di), Modern Political Parties, Chicago, Chicago University Press, pp. 395-421.

Panebianco, A. (1982), Modelli di partito, Bologna, Il Mulino.

Pappalardo, A. (1989), I sindacati prefascisti. Ricostruzione e verifica di ipotesi, Firenze, Edizioni Polistampa.

Pelling, H. (1965), The Origins of the Labour Party, London, Oxford University Press.

- (1969), A History of British Trade Unionism, London, Macmillan.

Pizzorno, A. (1966), Introduzione allo studio della partecipazione politica, in «Quaderni di Sociologia», XV, pp. 235-287.

Pride, R.A. (1970), Origins of Democracy: A Cross National Study of Mobilization, Party Systems and Democratic Stability, Beverly Hills, Sage.

Przeworski, A. (1985), Capitalism and Social Democracy, Cambridge, Cambridge University Press.

Przeworski, A. e J. Sprague (1986), Paper Stones. A History of Electoral Socialism, Chicago, University of Chicago Press.

Reymond-Sauvain, P. (1966), Le syndicalisme en Suisse, Genève, Editions Générales.

Roberts, R. (1958-59), Appendix, in «Journal of the Statistical and Social Inquiry Society of Ireland», XX, p. 95.

Roche, W.K. (1990), A Model Working Class? The Liberal Theory of Industrialization and the Maturation of the Irish Labour Movement, relazione presentata alla «Conference on the Development of the Industrial Society in Ireland», Oxford, Nuffield College, dicembre 1990.

Roche, W.R. (1992), Modelling Trade Union Growth and Decline in the Republic of Ireland, in «IBAR, Irish Business and Administrative Research», 13, pp. 86-102.

Rokkan, S. (1970), Nation Building, Cleavages Formation and the Structuring of Mass Politics, in Citizens Elections Parties, Oslo, Universitetsforlaget, pp. 72-144, trad. it. in Cittadini Elezioni Partiti, Bologna, Il Mulino, 1982, pp. 131-229. 
- (1977), Toward a Generalized Concept of «Verzoiling»; A Preliminary Note, in «Political Studies», XXV, pp. 563-570.

Rokkan, S. e H. Valen (1962), The Mobilization of the Periphery: Data on Turnout, Party Membership and Candidate Recruitment in Norway, in S. Rokkan (a cura di), Approaches to the Study of Political Participation, Bergen, Christian Michelsen Institute, pp. 111158.

Sani, G. e G. Sartori (1978), Frammentazione, polarizzazione e cleavages: democrazie facili e difficili, in «Rivista Italiana di Scienza Politica», XVIII, pp. 339-62.

Schorske, C.E. (1955), German Social Democracy 1905-1917, Boston, Harvard University Press.

Spitaels, G. (1974), Le Mouvement syndical en Belgique, Bruxelles, Editions de l'Université de Bruxelles.

Steenson, G.P. (1991), After Marx, Before Lenin. Marxism and Socialist Working-Class Parties in Europe, 1884-1914, Pittsburgh, University of Pittsburgh Press.

Steiner, H. (1964), Die Arbeiterbewegung Oesterreichs 1867-1889, Wien.

Suviranta, A.J. (1987), Finland, in R. Blainpain (a cura di), International Encyclopedia for Labour Law and Industrial Relations, Deventer, Kluwer.

Svasand, L. (1978), On the Formation of Political Parties: Conditions, Causes and Patterns of Development, relazione presentata al Workshop ECPR, Grenoble, aprile 1978.

Sworatowski, W.S. (a cura di) (1973), World Communism: A Handbook, Washington, Hoover Institution Press.

Szabo, E. (1982), Socialism and Social Science. Selected Writings of Ervin Szabo (1877-1918), a cura di G. Lituan e J. Back, London, Routledge and Kegan Paul.

Tilly, C. (1978), From Mobilization to Revolution, Reading, Mass., Addison-Wesley.

Työministeriö (1990), Työelämän Subteet - Aikasarjola 1907-1988, Helsinki, Työministeriö.

Val Lorwin, R. (1954), The French Labour Movement, Boston, Harvard University Press.

- (1971), Segmented Pluralism, Ideological Cleavages and Political Cohesion in the Smaller European Democracies, in «Comparative Politics», III, pp. 147-187.

Visser, J. (1987), In Search of Inclusive Unionism. A Comparative Analysis, University of Amsterdam, PhD Dissertation.

- (1992), Trade Union Membership Database, Amsterdam, Department of Sociology.

Vuilleumier, M. (1988), Autour de la «fondation» du Parti Socialiste Suisse, in Les origines du Socialisme en Suisse Romande 1880-1920, Lausanne, Association pour l'Etude du Mouvement Ouvrier, Cahier n. 5. 